\title{
Arcjet Testing and Thermal Model Development for Multilayer Felt Reusable Surface Insulation
}

\author{
F.S. Milos* \\ NASA Ames Research Center, Moffett Field, CA 94035-1000 \\ Carl D. Scott ${ }^{\dagger}$ \\ LZ Technology, Houston, TX 77058 \\ and \\ Steven V. Del Papa \\ NASA Johnson Space Center, Houston, TX 77058
}

\begin{abstract}
Felt Reusable Surface Insulation was used extensively on leeward external surfaces of the Shuttle Orbiter, where the material is reusable for temperatures up to $670 \mathrm{~K}$. For application on leeward surfaces of the Orion Multi-Purpose Crew Vehicle, where predicted temperatures reach $1620 \mathrm{~K}$, the material functions as a pyrolyzing conformal ablator. An arcjet test series was conducted to assess the performance of multilayer Felt Reusable Surface Insulation at high temperatures, and a thermal-response, pyrolysis, and ablation model was developed. Model predictions compare favorably with the arcjet test data.
\end{abstract}

\section{Nomenclature}

\begin{tabular}{|c|c|c|c|}
\hline \multicolumn{2}{|c|}{ symbols } & \multicolumn{2}{|l|}{ subscripts } \\
\hline A & $=$ reaction pre-exponential constant, $1 / \mathrm{s}$ & $c$ & $=$ char \\
\hline E & $=$ reaction activation temperature, $\mathrm{K}$ & $g$ & $=$ pyrolysis gas \\
\hline$h$ & $=$ static enthalpy, $\mathrm{J} / \mathrm{kg}$ & $i$ & $=$ decomposition reaction number \\
\hline$\Delta h$ & $=$ heat of ablation, $\mathrm{J} / \mathrm{kg}$ & $v$ & $=\operatorname{virgin}($ original) value \\
\hline$P$ & $=$ pressure, $\mathrm{kg} / \mathrm{m}-\mathrm{s}^{2}$ & $w$ & $=$ wall $($ surface $)$ value \\
\hline$q_{\text {cond }}$ & $=$ conductive heat flux, $\mathrm{W} / \mathrm{m}^{2}$ & \multicolumn{2}{|c|}{ acronyms and abbreviations } \\
\hline$q_{s}$ & $=$ surface heat flux, $\mathrm{W} / \mathrm{m}^{2}$ & AETB & $=$ Alumina Enhanced Thermal Barrier \\
\hline$\dot{s}$ & $=$ recession rate, $\mathrm{m} / \mathrm{s}$ & CFD & $=$ Computational Fluid Dynamics \\
\hline$T$ & $=$ temperature, $\mathrm{K}$ & FIAT & $=$ Fully Implicit Ablation and Thermal response \\
\hline$T_{\infty}$ & $=$ environment temperature, $\mathrm{K}$ & FRSI & $=$ Felt Reusable Surface Insulation \\
\hline$t$ & $=$ time, $\mathrm{s}$ & ISS & $=$ International Space Station \\
\hline$w$ & $=$ volume change fraction & MPCV & $=$ Multi-Purpose Crew Vehicle \\
\hline$\varepsilon$ & $=$ emissivity & RCG & $=$ Reaction Cured Glass \\
\hline$\rho$ & $=$ density, $\mathrm{kg} / \mathrm{m}^{3}$ & RTV & $=$ Room Temperature Vulcanizing \\
\hline$\sigma$ & $=$ Stefan-Boltzmann constant, $\mathrm{W} / \mathrm{m}^{2}-\mathrm{K}^{4}$ & SIP & $=$ Strain Isolation Pad \\
\hline$\Phi$ & $=$ volume ratio & $\mathrm{TC}$ & $=$ Thermocouple \\
\hline$\psi$ & $=$ reaction density exponent & TUFI & $=$ Toughened Uni-piece Fibrous Insulation \\
\hline & & XRD & $=\mathrm{X}$-Ray Diffraction \\
\hline
\end{tabular}

\footnotetext{
* Aerospace Engineer, Thermal Protection Materials Branch, Mail Stop 234-1. Senior Member AIAA.

${ }^{\dagger}$ Consultant, 492 Enchanted Oak, New Braunfels, TX 78132. Associate Fellow AIAA.

* Aerospace Engineer, Thermal Design Branch, Mail Stop ES3. Member AIAA.
} 


\section{Introduction}

Felt Reusable Surface Insulation (FRSI) is a heat-treated Nomex felt blanket with an outer mold line layer of white RTV silicone elastomer. ${ }^{1}$ For Shuttle Orbiter applications, nominal FRSI thicknesses of 4 and $8 \mathrm{~mm}$ were used in different leeward locations depending on the anticipated heat load during re-entry. The FRSI was bonded directly to the Orbiter structure using RTV-560 silicone adhesive. The white RTV coating was used to waterproof the felt and to provide the required surface optical properties. FRSI covered a significant fraction of the Orbiter's upper surfaces due to its light weight and the relatively low temperatures and heating rates encountered on these leeward surfaces. ${ }^{2}$ The material is reusable up to $672 \mathrm{~K}$ which is below the pyrolysis temperature of the Nomex and RTV constituents.

FRSI is the baseline material for some leeward locations on the Orion Multi-Purpose Crew Vehicle (MPCV). In these locations, for margined ISS and Lunar-return environments, the predicted maximum surface temperatures approach 1170 and $1620 \mathrm{~K}$, respectively. Clearly FRSI cannot be reusable in such environments. Nevertheless, a multilayer stackup of FRSI may perform acceptably as a conformal and insulative pyrolyzing ablator.

This paper describes an arcjet test series that was conducted to assess the thermal and ablative performance of multilayer FRSI at high temperatures, the development of a material-response model, and finally comparisons of model predictions with the arcjet test data.

\section{Arcjet Models and Data}

All samples were tested in the Test Position 2 (TP2) arcjet configuration at NASA Johnson Space Center. The arcjet test fixture is the copper wedge shown in Figure 1. The leading edge is water cooled. The top surface contains a rectangular cavity to accommodate a flush-mounted test or calibration article with dimensions up to $15.24 \times 15.24$ x $5.08 \mathrm{~cm}$. For this test series, the fixture was inserted, as illustrated in Figure 2, with the flow axis (centerline) impingement slightly aft of the center of the test section. The test surface was inclined to the flow at angles of 15 , 30 , or 45 degrees, with higher inclination angles producing greater heat flux and pressure. Surface temperature was measured using optical pyrometers focused at the center of the $15.24 \times 15.24 \mathrm{~cm}$ test square. For most tests conditions, a dual-instrument calibration model also was inserted to the centerline (in a separate run or on a different sting arm) to measure the stagnation point pressure and cold-wall heat flux. The test gas was simulated air containing $23 \%$ oxygen and $77 \%$ nitrogen by mass.

The wedge calibration model was a RCG and TUFI-coated AETB tile bonded to an aluminum plate with a strain isolation pad and RTV-560 (Figure 3). To measure the surface temperature, three Type-R thermocouples were located atop the TUFI layer just below the RCG surface layer. Arcjet conditions were adjusted to achieve specific values of surface temperature, which were confirmed using the thermocouple and pyrometer data.

The test articles consisted of five FRSI layers bonded together and to an aluminum plate with RTV-560 (Figure 4). The nominal thicknesses of the FRSI layer, the RTV-560 bond lines, and the aluminum plate were 8.13, 0.254 , and $3.81 \mathrm{~mm}$, respectively. During assembly, the FRSI is pressed into the RTV-560 and may not recover its original thickness; consequently, the final FRSI thickness varied from 7.11 to $8.13 \mathrm{~mm}$. Type-K thermocouples were placed at the center of the model at the front surface just below the white coating, in each bond line, and at the back of the aluminum plate. For most runs the surface thermocouple (TC1) performed oddly, probably because it became exposed to the flow, but the other six (TC2 to TC7) provided usable data. Post test samples were laser scanned to measure the residual height, then cross sectioned in one or two locations to reveal the char depth. For post-test samples with multiple layers of charred FRSI, the outermost layers tended to be poorly attached, and char pieces often fell off during post-test handling. Therefore, the amount of char observed in post test scans and cross sections may be less than the char thickness that was attached (or partially attached) to a sample during the test. 


\section{Test Conditions}

Test conditions were selected from margined aeroheating environments on leeward locations that were estimated for ISS and Lunar-return trajectories. For the most severe environments, the predicted maximum surface pressure and shear were low, below $1 \mathrm{kPa}$ and $48 \mathrm{~Pa}$, respectively. The predicted heat flux for severe ISS and Lunar return environments are shown by the black curves in Figures $5 \mathrm{a}$ and $5 \mathrm{~b}$, respectively. The maximum heat flux and its approximate duration are $8 \mathrm{~W} / \mathrm{cm}^{2}$ and 100 seconds for ISS return, and $30 \mathrm{~W} / \mathrm{cm}^{2}$ and 25 seconds for Lunar return. The red dotted lines in Figures $5 \mathrm{a}$ and $5 \mathrm{~b}$ show suggested "stepped" arcjet heating profiles to approximate the heat flux and load for each environment.

The test matrix in Table 1 considered four conditions of steady heating at different wedge angles, designated as conditions A to D, a stepped profile at 15-degree wedge angle to approximate the ISS environment, and a stepped profile at 45-degree wedge angle to approximate the Lunar environment. The stepped environments have red labels in Figures $5 \mathrm{a}$ and $5 \mathrm{~b}$.

Unfortunately, the wedge pressure was not measured (this problem was addressed in later wedge test series), and instead was roughly estimated using the stagnation pressure, an inclination angle factor, and a relaxation factor derived from CFD solutions for other wedge geometries. For most conditions, the estimated wedge pressure exceeded the range expected for relevant flight environments.

For several of the arcjet calibration runs, the temperature data showed both heatup and cooldown of the surface. Two examples are provided in Figure 6. In the first example, a room-temperature model was heated at condition ISS1, followed by a step change to condition A (see Table 1), before the model was removed from the arcjet flow. In the second example, a room-temperature model was exposed to condition D, followed by cooldown. The pyrometer data, thermocouple data, and one-dimensional FIAT predictions ${ }^{3}$ (to be described below) are shown as black, blue, and red curves, respectively. The pyrometers were unable to measure surface temperatures below about $1250 \mathrm{~K}$. Above this value, the pyrometer data closely matched the measurements from thermocouple TC2 that was located just beneath the RCG coating at the center of the tile (Figure 3).

For simulation of the FRSI response, to be considered in a later section, a reliable estimate of the surface heat flux is needed for each test condition in Table 1. To this end, the calibration runs were simulated using the FIAT code with the "option 3 " surface energy balance

$$
q_{s}=\sigma \varepsilon_{w}\left(T_{w}^{4}-T_{\infty}^{4}\right)+q_{c o n d}+\rho_{w} \dot{s} \Delta h
$$

Table 1. Arcjet test conditions

\begin{tabular}{|c|c|c|c|c|c|c|}
\hline $\begin{array}{c}\text { Test } \\
\text { Condition }\end{array}$ & $\begin{array}{c}\text { Descriptive } \\
\text { Name }\end{array}$ & $\begin{array}{c}\text { Wedge Angle } \\
\text { (degrees) }\end{array}$ & $\begin{array}{c}\text { Stagnation } \\
\text { Pressure } \\
\text { (kPa) }\end{array}$ & $\begin{array}{c}\text { Wedge } \\
\text { Pressure } \\
\text { (kPa) } \\
\text { Estimated }\end{array}$ & $\begin{array}{c}\text { Wedge } \\
\text { Heat Flux } \\
\left(W / \mathrm{cm}^{2}\right) \\
\text { Target }\end{array}$ & $\begin{array}{c}\text { Wedge } \\
\text { Heat Flux } \\
\left(W / \mathrm{cm}^{2}\right) \\
\text { Calculated }\end{array}$ \\
\hline $\mathrm{A}$ & Sublayer & 15 & 1.33 & 0.39 & 2.84 & 2.95 \\
\hline $\mathrm{B}$ & Max ISS & 30 & 3.74 & 1.93 & 11.4 & 12.9 \\
\hline $\mathrm{C}$ & Intermediate & 30 & 7.71 & 3.95 & 19.3 & 21.5 \\
\hline $\mathrm{D}$ & Max Lunar & 45 & not measured & $<10$ & 30.6 & 39.6 \\
\hline ISS1 & \multirow{2}{*}{$\begin{array}{l}\text { ISS-Return } \\
\text { Profile } \\
\text { (Figure 5a) }\end{array}$} & \multirow{2}{*}{15} & 1.20 & 0.34 & 2.27 & 2.55 \\
\hline ISS2 & & & 6.27 & 1.82 & 7.94 & 8.17 \\
\hline L1 & \multirow{4}{*}{$\begin{array}{c}\text { Lunar-Return } \\
\text { Profile } \\
\text { (Figure 5b) }\end{array}$} & \multirow{4}{*}{45} & 3.97 & 2.84 & 22.7 & 21.1 \\
\hline L2 & & & not measured & $<10$ & 29.5 & 35.1 \\
\hline L4 & & & 1.20 & 0.85 & 1.13 & 8.40 \\
\hline L5 & & & 1.67 & 1.22 & 11.4 & 12.6 \\
\hline
\end{tabular}


The left-hand side is the convective heat flux to be determined. On the right-hand side, the first term containing parentheses is the net radiation out, the second term is conduction into the tile, and the last term is zero for RCG which is non-ablating. The emissivity of "used" RCG coating, ${ }^{4}$ such as that found on the calibration tile, is approximately 0.75 in the temperature range of interest. By comparing FIAT predictions with data from all the calibration runs, it was possible to estimate the areal mass of the TUFI layer and an average environment temperature for radiation during cooldown $\left(T_{\infty} \approx 395 \mathrm{~K}\right)$ which is significantly above room temperature. The calculated heat flux is provided in the final column of Table 1. Except for condition L1, the targeted heat fluxes were exceeded, especially condition L4 because the low target heat flux was not achievable with a $45^{\circ}$ wedge angle.

\section{Thermal Models}

Multilayer FRSI contains both Nomex felt and RTV-560 adhesive. The RTV is only 3\% of the total thickness, but $34.5 \%$ of the total mass because of its high density. This significant mass fraction must be included in the thermal analyses; therefore, models are required for both materials. The thermal properties of virgin FRSI and RTV have been measured up to their respective re-use temperatures. For application to MPCV, however, properties are required up to at least $1650 \mathrm{~K}$, and the thermal decomposition must be modeled. The white-RTV coating is very thin and may be neglected in thermal analyses, except for its initial optical properties prior to charring.

\section{A. FRSI Nomex model}

Thermogravimetric analysis of Nomex was performed in an inert atmosphere at heating rates of 5 to $20 \mathrm{~K} / \mathrm{min}$. The shape of the derivative curve suggested to use a four-reaction decomposition model. The FIAT code was modified to allow up to four reactions according to the equation

$$
\rho=\rho_{c}+\sum \rho_{i} \quad \text { and } \quad \frac{d \rho_{i}}{d t}=-A_{i} \rho_{i v} \exp \left(E_{i} / T\right)\left(\frac{\rho_{i}}{\rho_{i v}}\right)^{\psi_{i}} \text { for } \quad i=1,4
$$

In this model, each density component $\rho_{i}$ decreases from its initial value $\rho_{i v}$ to zero. Model parameters were obtained by fitting the data at all three heating rates. The four-reaction model agrees well with the data as illustrated in Figure 7. The char yield is $50 \%$.

Like most organic materials, Nomex shrinks as it chars. The FRSI Nomex felt does not contain any nonshrinking matrix material, such as carbon fibers, that could provide dimensional stability. Therefore, the material must decrease in volume as it chars. As an illustrative example, Figure 8 presents a cross section of a post-test sample. The bottom ply (ply 5) is virgin, ply 4 is partially charred and shrunk, and ply 3 is well charred and shrunk. It is difficult to see, but (depending on location) ply 2 is partly ablated and ply 1 has mostly ablated. For post-test samples with subsurface charred layers, the thickness shrinkage varied from 30 to $50 \%$. This thickness variability occurs because the in-plane shrinkage is a somewhat uncontrolled phenomenon that depends on the integrity and proximity of free and/or bonded surfaces. In some samples the in-plane (lateral) shrinkage was constrained, probably by sufficient bond integrity, and the dimensional change was greater in the through-the-thickness direction. In other cases, however, lateral shrinkage caused the material to crack or disbond, and the thickness shrinkage was lessened. In any case, the magnitude of this shrinkage is sufficiently large such that the phenomenon should be considered in the thermal analyses.

Because volume change is related to the thermal decomposition, the following model was implemented in FIAT.

$$
\Phi=\Phi_{c}+\left(1-\Phi_{c}\right) \sum w_{i}\left(\frac{\rho_{i}}{\rho_{i v}}\right) \text { and } \sum w_{i}=1 \quad \text { for } i=1,4
$$


The relative volume is represented by the symbol $\Phi$. The material model requires as input the ratio of char-to-virgin volume $\Phi_{c}$ (shrinkage if $<1$, swelling if $>1$ ) and the volume change fractions $w_{i}$ for each decomposition reaction.

For the analyses presented herein, FRSI was assigned a char-to-virgin volume of $65 \%$ and default volume change fractions $w_{i}=\rho_{i v} / \sum \rho_{i v}$. The predicted char density is the virgin density times the char yield divided by $\Phi_{c}$.

Virgin and char composition of elements $\mathrm{H}, \mathrm{C}$ and $\mathrm{N}$ were measured. The virgin composition was within measurement uncertainty of the theoretical mole ratio of $\mathrm{C}_{7} \mathrm{H}_{5} \mathrm{NO}$ for the Nomex polymer that has the following molecular structure:

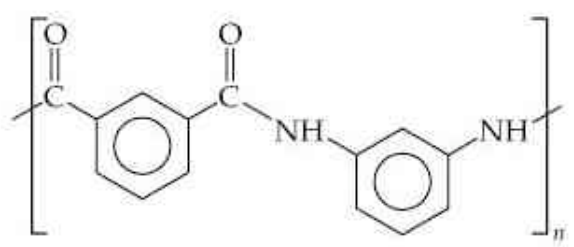

The char is approximately $95 \%$ carbon and 5\% nitrogen by mass. The average pyrolysis gas composition is calculated in Table 2 using the virgin and char elemental compositions and the char yield. For the virgin and char, the heat of formation was calculated from the measured heat of combustion (Table 3).

The TPSX database ${ }^{1}$ provides FSRI thermal properties obtained from Shuttle references. ${ }^{5-6}$ The specific heat is tabulated up to $589 \mathrm{~K}$ (virgin) and $811 \mathrm{~K}$ (partially charred). The specific heat (per $\mathrm{kg}$ ) of the fully-charred material should be slightly lower than that of graphite, owing to the substitution of $\mathrm{N}$ for $\mathrm{C}$. A small reduction was used to merge the char and virgin curves, as depicted in Figure 9. For partially charred material, the virgin and char values are interpolated based on density. The enthalpies of the virgin and char are calculated from the specific heat and the heats of formation.

The pyrolysis gas enthalpy can be estimated (for example using the ACE, MAT, or CEA $\operatorname{codes}^{7-9}$ ) for the average elemental composition in Table 2 and assuming equilibrium gas chemistry. At high temperatures, equilibrium gas chemistry is a good assumption. The gas enthalpy is a function of pressure, but the curves merge as temperature is reduced below $1500 \mathrm{~K}$. At low temperatures, chemical equilibrium is a poor assumption that leads to erroneous prediction of exothermic pyrolysis over a wide temperature range. To avoid this problem, and following an established practice, the gas enthalpy was linearized, and the slope was adjusted to achieve endothermic pyrolysis

Table 2. Element Mass Fractions for FRSI Nomex Model

\begin{tabular}{|c|c|c|c|}
\hline \hline Element & $\begin{array}{c}\text { Virgin } \\
\text { (ideal) }\end{array}$ & $\begin{array}{c}\text { Char } \\
\text { (measured) }\end{array}$ & $\begin{array}{c}\text { Pyro gas } \\
\text { (calculated) }\end{array}$ \\
\hline $\mathrm{H}$ & 0.0423 & -- & 0.0846 \\
\hline $\mathrm{C}$ & 0.7058 & 0.95 & 0.4616 \\
\hline $\mathrm{N}$ & 0.1176 & 0.05 & 0.1852 \\
\hline $\mathrm{O}$ & 0.1343 & -- & 0.2686 \\
\hline
\end{tabular}

Table 3. Density and Enthalpy Quantities for FRSI Nomex Model

\begin{tabular}{|c|c|c|}
\hline \hline Quantity & Virgin & Char \\
\hline Density, $\mathrm{kg} / \mathrm{m}^{3}$ & 86.5 & 43.25 \\
\hline Heat of combustion, $\mathrm{MJ} / \mathrm{kg}$ & 27.61 & 31.40 \\
\hline Heat of formation, $\mathrm{MJ} / \mathrm{kg}$ & -0.126 & 0.256 \\
\hline \hline
\end{tabular}


in the applicable temperature range. Figure 10 shows the adjusted line (black) and the resulting heat of pyrolysis (red), which is positive above $500 \mathrm{~K}$. This level of pyrolysis-gas modeling is relatively crude but nevertheless adequate for low-pressure applications $(<150 \mathrm{kPa})$ where energy storage in the gas phase is not a significant term in the in-depth energy equation.

Because FRSI is a material with open porosity, the thermal conductivity is a function of pressure. Specifically, as pressure is reduced, and the mean free path of gaseous species becomes comparable to the pore dimensions, the gas conductivity component of the effective thermal conductivity is reduced. Thermal conductivity of virgin FRSI also is available in TPSX. The TPSX tabulated data are indicated by hollow circles in Figure 11. Above $200 \mathrm{~K}$, the data range is too large. Specifically, on a theoretical basis, at any temperature the difference in conductivity between the highest and lowest pressures should not exceed the thermal conductivity of air at that temperature. For this work, the conductivity of virgin and char were estimated by comparison of predicted thermal response with thermocouple data. At each pressure, the lower and upper curves are for virgin and char, respectively. The difference between conductivity at the highest and lowest pressure was limited to conductivity of dry air. As seen in the figure, the estimated thermal conductivity is within the range of the TPSX data.

Thermochemical ablation modeling is the preferred approach to predict surface quantities of TPS materials in high-temperature applications. In this approach, the prescribed boundary condition quantities are surface pressure, heat transfer coefficient, and boundary-layer recovery enthalpy. These quantities typically are obtained from CFD solutions, an aerothermal database based on such solutions, and/or measured quantities in ground tests.

For the arcjet tests described in this work, the flowfield around the wedge is complex and three dimensional. In addition to the spreading of the flow away from the plane of symmetry, the main nozzle flow is deflected upward, and the boundary layer edge is somewhere in the periphery of the hot core. Unfortunately, CFD simulations are not available for any of the test conditions, and therefore the recovery enthalpy is unknown and practically impossible to estimate quantitatively. The pressure was not measured in the test section, and may be estimated for some conditions where a stagnation pressure was measured (Table 1). The only available data are pyrometer and thermocouple temperature measurements for the calibration model and for the test specimens, and post-test measurements of the ablated material. Based on the quality and quantity of available data, development and validation of a thermochemical ablation model for FRSI is not feasible at this time. Additionally, it is noted that in the intended flight application, on leeward surfaces of MPCV, the boundary conditions quantities are likely to be only an approximate time history of heat flux and pressure. Therefore, a thermochemical ablation model would be difficult to use, even if a validated model was available.

Based on the preceding discussion, the approach taken in this work was to correlate the recession rate of FRSI. Specifically a combined recession rate and heat of ablation model was developed, and this model was implemented into the "option 3" boundary condition of FIAT. The relevant portions of this boundary condition were given in Eq. (1). For each test condition, the input heat flux $q_{s}$ was derived from the applicable calibration run. The ablation rate was correlated as a function of temperature (Figure 12) mostly using data from test conditions A to D. The total ablation was obtained from post-test measurements of surface recession and from observation of cross sections. The total ablation is the total recession minus the shrinkage which is modeled and calculated separately using Eq. (3) in FIAT.

For every test condition, the FRSI surface temperature exceeded that of calibration plate, and this difference was greatest at high heating conditions where the char emissivity also is high. This result suggested that the temperature increase was related to exothermic oxidation of the fibers. The heat of combustion (negative of $\Delta h$ ) was estimated mostly using data from test conditions A to D. The apparent heat of combustion lies within the expected range of 9 to $33 \mathrm{MJ} / \mathrm{kg}$ for oxidation of carbon to $\mathrm{CO}$ and $\mathrm{CO}_{2}$, respectively. In the less severe environments, the oxygen partial pressure is too low to obtain complete oxidation to $\mathrm{CO}_{2}$. Additionally, spallation probably is significant and decreases the apparent heat of combustion. The plotted values in Figure 12 are consistent with spallation on the order of $20 \%$. 
At low heating conditions, where the ablation rate is small, the temperature difference between FRSI and the calibration plate is attributed to differences in surface emissivity or and/or catalycity. The quantitative effects of surface catalysis are difficult to assess without CFD simulations. For emissivity, post-test photos show that the char color varies from yellow/white at very low heating rates, to orange/brown at intermediate conditions, to black at the highest heating rate. Based on observed surface temperatures, the char emissivity seems to increase from about 0.55 at $800 \mathrm{~K}$ to about 0.8 at $1800 \mathrm{~K}$ (Figure 13 ). The white RTV coating is assigned a virgin emissivity of 0.8 from TPSX.

\section{B. RTV-560 model}

Thermogravimetric analysis of RTV-560 was performed in an inert atmosphere and in air at heating rates of 5 to $20 \mathrm{~K} / \mathrm{min}$. For this material, both the char yield and the number of reactions are variable. In an inert environment, or for relatively thick samples in air, there are two decomposition reactions. The primary reaction is centered near $775 \mathrm{~K}$, and a secondary reaction occurs near $1075 \mathrm{~K}$. The char yield in the inert atmosphere is 40 to $45 \%$. In air for samples with large surface-to-volume ratio, the primary reaction has more features, and the secondary reaction is not observed. The char yield in air is 45 to $50 \%$. In the former case, XRD analysis shows the char is mostly fayalite $\left(\mathrm{Fe}_{2} \mathrm{SiO}_{4}\right)$, whereas in the latter case, the char is mostly hematite and cristobalite $\left(\mathrm{Fe}_{2} \mathrm{O}_{3}\right.$ and $\left.\mathrm{SiO}_{2}\right)$. The presence of oxygen seems to suppress the secondary reaction which is the production of fayalite:

$$
\mathrm{Fe}_{2} \mathrm{O}_{3}+\mathrm{SiO}_{2} \rightarrow \mathrm{Fe}_{2} \mathrm{SiO}_{4}+\frac{1}{2} \mathrm{O}_{2}
$$

For bonded multilayer FRSI in an Earth-entry application, the layers of RTV-560 are thin, and oxygen is present. Therefore, it is appropriate to use a one-reaction decomposition model and an average char yield of $45 \%$. In Figure 14, model predictions are compared with two different thermogravimetric experiments that show the reaction variability.

Virgin and char composition of elements $\mathrm{H}, \mathrm{C}, \mathrm{Si}$, and Fe were measured (Table 4). The oxygen value is that required to achieve a sum of unity. The virgin material contains $\mathrm{Fe}_{2} \mathrm{O}_{3}$ catalyst and silicone with a hydrocarbon content very close to $\mathrm{C}_{2} \mathrm{H}_{5}$. The char contained no measureable $\mathrm{H}$ or $\mathrm{C}$, and $\mathrm{Fe}_{2} \mathrm{O}_{3}$ does not vaporize in the temperature range of pyrolysis. Therefore, based on the virgin composition and the assumed yield of $45 \%$, the char contains approximately $64 \% \mathrm{Fe}_{2} \mathrm{O}_{3}$ and $36 \% \mathrm{SiO}_{2}$ by mass. The average pyrolysis gas composition is calculated from the other quantities. The gas contains $\mathrm{SiO}$ and perhaps some higher molecular weight $\mathrm{Si}_{\mathrm{x}} \mathrm{O}_{\mathrm{y}}$ species which tend to condense as an amorphous mess on surfaces, especially during cooldown. For the virgin material, the heat of formation was calculated from the measured heat of combustion. The heat of formation of the char was calculated from known values for its oxide constituents (Table 5).

The char specific heat was calculated from known values for the constituents. Phase transitions were smoothed out to produce the black curve shown in Figure 15. The virgin specific heat is available in TPSX from Shuttle references. ${ }^{5-6}$ The data were extrapolated, and then the slope was changed to merge the virgin (red) curve into the char (black) curve in the temperature range of 690 and $990 \mathrm{~K}$ where pyrolysis occurs. The intent here is merely to assure that the calculated specific heat smoothly transitions from virgin to char during pyrolysis. The thermal conductivity of virgin and char also are available from TPSX (Figure 16). Again, the data were extrapolated, and then the slope of the virgin (red) curve was changed to merge the virgin and char property values between 690 and $990 \mathrm{~K}$. A constant emissivity of 0.8 from TPSX was used.

Using the same procedure discussed previously, the pyrolysis gas enthalpy was calculated for the average elemental composition and assuming equilibrium gas chemistry. The curves merge near $1500 \mathrm{~K}$, and a linear section was used at low temperatures to achieve endothermic pyrolysis for temperatures above $500 \mathrm{~K}$.

Insufficient data are available to develop and validate an ablation model for RTV-560. For analysis of multilayer FRSI, currently the Nomex ablation model is used during the short time periods where charred RTV-560 is the 
surface material. Although this approach is technically incorrect, in FIAT calculations the thin RTV layer is predicted to ablate very rapidly without adversely affecting the in-depth thermal response. This predicted response agrees with the observed behavior in the arcjet tests.

\section{FRSI Test Results and Model Predictions}

A total of ten multilayer FRSI samples were tested at the conditions and durations listed in Table 6. Two samples were tested at each of the four constant conditions A to D, and one sample was exposed to each stepped profile. Results will be discussed sequentially following the order they are listed in the table.

Table 4. Element Mass Fractions for RTV-560 Model

\begin{tabular}{|c|c|c|c|}
\hline \hline Element & Virgin & Char & $\begin{array}{c}\text { Pyro gas } \\
\text { (calculated) }\end{array}$ \\
\hline $\mathrm{H}$ & 0.0472 & -- & 0.0858 \\
\hline $\mathrm{C}$ & 0.2273 & -- & 0.4133 \\
\hline $\mathrm{O}$ & 0.3095 & 0.3844 & 0.2482 \\
\hline $\mathrm{Si}$ & 0.2150 & 0.1689 & 0.2527 \\
\hline $\mathrm{Fe}$ & 0.2010 & 0.4467 & -- \\
\hline
\end{tabular}

Table 5. Density and Enthalpy Quantities for RTV-560 Model

\begin{tabular}{|c|c|c|}
\hline \hline Quantity & Virgin & Char \\
\hline Density, $\mathrm{kg} / \mathrm{m}^{3}$ & 1410 & 634.5 \\
\hline Heat of combustion, $\mathrm{MJ} / \mathrm{kg}$ & 15.89 & not measured \\
\hline Heat of formation, $\mathrm{MJ} / \mathrm{kg}$ & -4.23 & -8.78 \\
\hline \hline
\end{tabular}

Table 6. Multilayer FRSI Test Matrix

\begin{tabular}{|c|c|c|c|c|}
\hline Test Condition & $\begin{array}{c}\text { Heat Flux } \\
\left(W / \mathrm{cm}^{2}\right) \\
\text { Calculated }\end{array}$ & Sample ID & $\begin{array}{c}\text { Exposure Time } \\
\text { (sec) }\end{array}$ & $\begin{array}{l}\text { Total Heat Load } \\
\qquad\left(\mathrm{kJ} / \mathrm{cm}^{2}\right)\end{array}$ \\
\hline \multirow{2}{*}{ A (sublayer) } & \multirow{2}{*}{2.95} & 3033 & 900 & 2.66 \\
\hline & & 3032 & 970 & 2.86 \\
\hline \multirow{2}{*}{ B (max ISS) } & \multirow{2}{*}{12.94} & 3030 & 500 & 6.45 \\
\hline & & 3029 & 600 & 7.74 \\
\hline \multirow{2}{*}{$\mathrm{C}$ (intermediate) } & \multirow{2}{*}{21.45} & 3028 & 60 & 1.29 \\
\hline & & 3031 & 100 & 2.15 \\
\hline \multirow{2}{*}{ D (max Lunar) } & \multirow{2}{*}{39.61} & 3034 & 28 & 1.11 \\
\hline & & 3035 & 58 & 2.30 \\
\hline ISS-Return Profile & 2.55 to $8.17^{*}$ & 3036 & 648 & 2.66 \\
\hline Lunar-Return Profile & 8.40 to $35.1^{\dagger}$ & 3037 & 652 & 7.37 \\
\hline
\end{tabular}

* Steps ISS1 for $450 \mathrm{~s}$, ISS2 for $180 \mathrm{~s}$, ISS1 for $18 \mathrm{~s}$.

$\uparrow$ Steps L1 for $25 \mathrm{~s}, \mathrm{~L} 2$ for $25 \mathrm{~s}, \mathrm{~L} 1$ for $30 \mathrm{~s}$, L4 for $320 \mathrm{~s}, \mathrm{~L} 5$ for $125 \mathrm{~s}$, L4 for $127 \mathrm{~s}$. 
For each test condition, FIAT simulations use the boundary condition from Eq. (1) with prescribed input heat flux calculated for the applicable calibration run(s) of Table 1. The ablating surface may experience a slightly different convective heat flux than the RCG-coated calibration plate. Specifically, the heating is reduced by blowing of pyrolysis gas into the boundary layer, but may be increased if the char has greater catalycity for atom recombination. The net result of these two competing effects is difficult to assess with the level of ablation modeling considered in this work. The additional effects of surface emissivity and heat of ablation are accounted in other terms in Eq. (1). If surface recession becomes significant, then the flowfield can be affected which will change the heat flux magnitude and distribution in the test cavity.

The FRSI is bonded to an aluminum plate that is in contact with the copper text fixture. The front portion of the plate loses heat to the water-cooled leading edge, and the back surface may be heated by hot gas that flows around the wedge. Because the heat flux to or from the aluminum backplate is an unknown function of time, the back-face temperature history (from thermocouple TC7) was used as the second thermal boundary condition in the FIAT analyses.

Samples 3033 and 3032 were exposed to test condition A for 900 and 970 seconds, respectively. Figures 17ab presents photographs of two cross sections and an oblique view of each sample. Here, and in all similar figures to follow, the flow is from left to right. As illustrated in the oblique views, for all samples the first cross section removed about one-third of the sample, and the second cross section cut through the center of the sample. The second cross section therefore typically shows red RTV and/or holes where the thermocouple wires were located. All cross sections were photographed with an inch ruler on the left (upstream) side. The FRSI plies are slightly thinner in sample 3032 than in sample 3033. This thickness variation probably resulted from differences in pressure load or duration during bonding, as specifications for this process were not fully developed at the time this work was performed.

For both samples, the ablated surface is uncracked and only slightly irregular. The color is a mixture of brown Nomex, darker char, and whiteish residual from RTV pyrolysis. The top surface shrank in area, to less than $15.24 \mathrm{x}$ $15.24 \mathrm{~cm}$, and consequently pulled away from sides of the metal enclosure. This areal shrinkage caused flow irregularities that increased the aeroheating and ablation around the periphery of the sample. Nevertheless, probably the flow and heating were relatively uniform in the central portion of the test square where all the data were taken. The cross sections show that in the central area, ply 1 is charred, shrunk, and only slightly ablated, and ply 2 is partially charred. Deeper plies 3 to 5 are still virgin.

Figure 18 compares the temperature data from the two samples during the arcjet exposure. The pyrometer data are consistent, but unreliable as mentioned previously for surface temperature below $1250 \mathrm{~K}$. Sample 3032 shows greater in-depth temperatures at all thermocouple locations. It is unclear whether this difference is normal sampleto-sample variation or a result of the reduced ply thickness in sample 3032.

Data and one-dimensional FIAT predictions are compared in Figures 19a and 19b for samples 3033 and 3032, respectively. For in-depth temperatures, the agreement is fairly good, considering the extremely long time scale in these tests. The calculations match the peak temperatures better for sample 3033, and the time-to-peak better for sample 3032. On a long time scale, the samples cool less rapidly than predicted by FIAT. The data suggest that on a long time scale, the center of the sample receives some additional heat load by lateral conduction in from the periphery. FIAT predicts less than $0.2 \mathrm{~mm}$ of ablation, but over $3 \mathrm{~mm}$ of total recession owing to shrinkage. These values are consistent with the cross section photos.

For condition B the total heat load was more than doubled from that of condition A. Samples 3030 and 3029 were exposed to test condition B for 500 and 600 seconds, respectively. Figure 20 compares the temperature data from the two samples during the arcjet exposure. The data are somewhat consistent for the first 250 seconds. Then for sample 3030, ply 1 started to delaminate, and a large piece detached near the thermocouple location at 300 seconds. All temperatures rose sharply (the green curves), and consequently the data are not useful for model validation. Sample 3029, however, was successfully tested for 600 seconds without any such major delamination. 
Figure 21 presents photographs of two cross sections and an oblique view of sample 3029. Some pieces of char fell off during post-test handling. The lateral shrinkage was more severe here than for condition $\mathrm{A}$. The cross sections show that ply 5 is virgin, ply 4 is partly charred, and plies 2-3 are well charred. Too much char was lost to determine a quantitative value for surface ablation. It looks like most of ply 1 ablated or failed, but very little of ply 2 was ablated near the center of the sample. The surface color is a mixture of black from carbon and silver/white from silicone decomposition.

Despite problems with the near-surface behavior of the material, the model predictions compare very well with the thermocouple data (Figure 22). The back plate temperature from thermocouples TC7 is strange; clearly heating and then cooling is being caused by some effect other than heat conduction through the thickness. The surface temperature prediction crosses through the pyrometer data that are irregular, probably because small pieces of ply 1 were falling off during the test. FIAT predicts ply 1 to fully ablate at 590 seconds, as indicated by the intersection of the two red curves for Tw and TC2 in Figure 22.

Condition $\mathrm{C}$ has higher heat flux but shorter duration with lower total heat load than condition B. Samples 3028 and 3031 were exposed to the flow for 60 and 100 seconds, respectively. Figure 23 compares the temperature data from the two samples during the arcjet exposure. The pyrometer data are consistent and show an increase with time. The thermal penetration to TC2 is significantly faster for sample 3031, even though the ply thicknesses appear to be similar.

Figures 24ab presents photographs of two cross sections and an oblique view for each sample. The surface color is again is a mixture of mostly black with a few light areas. Lateral shrinkage at the perimeter is less than seen in condition B that had a longer duration. For both samples the ablating surface is irregular with shrinkage cracks and/or pits where material may have detached. The spacing of surface features is on the order of $20 \mathrm{~mm}$. For sample 3028, most of the surface is char of ply 1, and ply 2 is near virgin. For sample 3031, ply 1 is extensively ablated, cracked, or detached. Ply 2 is partly charred and starting to ablate in areas where it is exposed. The deeper plies 3 to 5 are virgin.

Temperature data are compared with model predictions in Figures 25 and 26 for samples 3028 and 3031, respectively. The plots on the left (Figures 25a and 26a), which use a linear time scale, show that the thermal model provides a fair approximation to the surface temperature Tw and the in-depth temperature TC3. During heatup the prediction for TC2 goes between the inconsistent data from the two samples. The plots on the right (Figures $25 \mathrm{~b}$ and 26b), which use a logarithmic time scale, show the thermal penetration to the deeper thermocouples. The thermal model slightly underpredicts the time to peak temperature and overpredicts the magnitude of the peaks. These results are considered to be conservative. FIAT predicts ply 1 to almost fully ablated in 100 seconds, as indicated by the near intersection of the two red curves for Tw and TC2 in Figure 26a.

Condition D is an over-test that exceeds the maximum predicted heating for Multilayer FRSI in a Lunar-return environment. Samples 3034 and 3035 were exposed to the flow for 28 and 58 seconds, respectively. The temperature data from the two samples are relatively consistent (Figure 27). Unfortunately, pyrometer data are not available for sample 3034 .

Figures 28ab presents photographs of two cross sections and an oblique view for each sample. For the shorterduration test (sample 3034) the surface is irregular, but not too damaged, with perhaps a darker color than seen previously. Ply 2 is starting to char. For the longer-duration test (sample 3035) the surface features have deepened to become cracks and pits. Ply 1 has ablated, ply 2 well charred and approximately half ablated, and ply 3 is nearly virgin.

Temperature data are compared with model predictions in Figures 29 and 30 for samples 3034 and 3035, respectively. Mixed results are obtained for these samples. The predicted surface temperature is slightly below the pyrometer measurement. For TC2, the predictions seem to be slightly delayed relative to the data. However FIAT correctly predicts ply 1 to fully ablate in 38 seconds, which is consistent with ablation of 1.5 plies in 60 seconds. In the experiment, there is no precise time for ablation of a ply, because a series of small pieces fall off the sample. The 
predicted maximum for TC3 is low for sample 3034 but high for sample 3035. For both samples, FIAT overpredicts the maximum temperature at the deeper thermocouples TC4 and TC5 (Figures 29b and 30b) which is the desired conservative result.

Heating for the ISS-return profile (Figure 5a) varies from below condition A in the first and third steps to below condition B in the second step. Figures 31 presents photographs of two cross sections and an oblique view of the sample. The ablated surface is very irregular with color variations of brown, black, and white. Lateral shrinkage is significant, and cracks are mostly aligned with the flow direction. The cross sections look more uniform than the oblique view, only because the side views conceal the indentations.

Ply 1 is fully charred but only slightly ablated, ply 2 is partly charred, and plies 3-5 are virgin. Model predictions and data are presented in Figures 32ab. The predicted surface temperature agrees with the pyrometer data in the second step. The pyrometer data are not accurate in the first step, because the surface temperature is below $1250 \mathrm{~K}$. For all thermocouples, the calculations overpredict the maximum in-depth temperatures and underpredict the time to the maxima. The cause of this discrepancy is unknown, but again the calculation error is considered to be conservative.

The Lunar-return profile environment (Figure $5 b$ ) was very severe. The heating varies from below condition B to below condition D. The remains of the post-test sample are shown in Figure 33. Ply 1 has ablated, some parts of ply 2 are present but hardly attached, ply 3 seems to be mostly attached except near the perimeter, ply 4 is well charred and attached, and ply 5 is partly charred. The oblique view shows damage in the central portion of the sample which could affect the TC data depending on when this damage occurred. A large piece of material detached at 90 seconds in the beginning of step L4. This material probably was from ply 2 , because ply 1 should be fully ablated before that time.

Temperature data are compared with model predictions in Figure 34. The FIAT surface temperature rises and falls with the six steps in the heat flux profile. The small blip at 74 seconds is the predicted ablation of the thin RTV layer between FRSI ply 1 and FRSI ply 2. This event is predicted to occur during environment step L3. The pyrometer data inexplicably do not show the transition from step L2 to step L3 between 50 and 80 seconds. The pyrometer is not accurate for steps L4 and L6. The TC2 prediction (red) precedes the data (black), but both curves indicate full ablation of ply 1 within step L3.

FIAT predicts that temperature TC3 should level off during the long exposure to mild environment L4. However, the TC3 data continue to rise and eventually cross above the data from the pyrometer at the beginning of step L5. To explain this odd behavior, it is suspected that either a crack formed, or a piece of ply 2 detached, near the thermocouple location, which caused higher-than-modeled heating to the bondline containing TC3. Subsequently, in response to the high heating near TC3, the in-depth temperatures rise faster than the FIAT predictions at the deeper thermocouples.

\section{Discussion}

FRSI felt is an excellent insulative material. Unfortunately, the felt is made of organic fibers that shrink significantly as they pyrolyze. As a consequence of this fiber shrinkage, the material must decreases in volume. Thickness shrinkage, which was modeled, does not directly cause performance issues. Lateral shrinkage, however, often leads to cracks and pits in the outermost ply, with spacing on the order of $20 \mathrm{~mm}$. The depth of these features increases with time and may reach down to the bond layer. Additionally, the strength of a charred RTV bond layer is poor, and consequently a fully charred layer of felt may be poorly attached to the underlying ply. As a combined result of these two phenomena, localized failure of small pieces of an exposed charred ply was observed in most arcjet environments considered in this work. The exceptions were the two lowest pressure/shear environments, conditions A and ISS1. The average ablation rate, including localized failures, was estimated from the thickness remaining in post-test cross sections. This rate is consistent with an overall failure rate on the order of $20 \%$ of the 
total surface mass loss. Nevertheless, as long as these surface failures remain small and localized, the multilayer material retains it good insulative capability in deeper plies.

For two of ten samples tested (3030 and 3037), large pieces of the ablating ply detached. It is unclear whether or not this large-scale failure is an artifact of the test design, where flow distubances occur near the periphery of the test cavity. For flight applications to leeward surfaces of MPCV, the estimated pressure and shear are lower than found in these tests, and it is possible that such large-scale failures will not occur. Nevertheless, to mitigate the possibility of large-scale ply failure, the recommendation for TPS sizing is to have at least two essentially uncharred FRSI plies at the end of the aerothermal heating. Additional charring by heat conduction during final cooldown in a nonablative environment is acceptable. Based on the analyses presented in this work, for thermal protection more than five layers of FRSI are necessary only near the peak heating location for the Lunar return environment.

\section{Conclusions}

Multilayer Felt Reusable Surface Insulation is the baseline material for some leeward locations on the Orion Multi-Purpose Crew Vehicle where the aeroheating is sufficiently high to cause pyrolysis and ablation. The material was successfully tested in a wedge configuration in the NASA Johnson Space Center arcjet facility at a variety of conditions relevant to ISS and Lunar-return trajectories. Concurrently, material response models were developed at Ames Research Center for both constituents of the material, specifically Nomex felt and RTV-560 adhesive. The Nomex model includes volumetric shrinkage during charring which is a significant phenomenon. One-dimensional material response predictions compared favorably with the arcjet test data over a range of test conditions.

\section{Acknowledgments}

This work was supported by the Orion Technology Development Project. The authors greatly appreciate the assistance of T. Nguyen for arcjet test data, M. Stackpoole for laboratory data, and M. Rezin for helpful discussions of FRSI.

\section{References}

[1] Squire, T. H., Milos, F. S., and Hartlieb, G. C., "Aerospace Material Property Database (TPSX)," Journal of Spacecraft and Rockets, Vol. 46, No. 3, 2009, pp. 733-736

[2] Anon, "Current Technology for Thermal Protection Systems," NASA CP 3157, Feb. 1992.

[3] Chen, Y.-K., and Milos, F.S., "Ablation and Thermal Analysis Program for Spacecraft Heatshield Analysis," Journal of Spacecraft and Rockets, Vol. 36, No. 3, 1999, pp. 475-483.

[4] Bouslog, S.A., and Cunnington, G.R., Jr., "Emittance Measurements of RCG Coated Shuttle Tiles," AIAA Paper 92-0851, Jan. 1992.

[5] Anon., "Materials Property Manual, Vol. 3, Thermal Protection System Materials Data," Rockwell International Publication 2543-W, Rev. 5-79, Aug. 1988.

[6] Anon., "Space Shuttle Program Thermodynamic Design Data Book. Penetrations," Rockwell International Report SD73-SH-0226, Jan. 1981.

[7] Kendall, R.M., "An Analysis of the Coupled Chemically Reacting Boundary Layer and Charring Ablator, Part V, A General Approach to the Thermochemical Solution of Mixed Equilibrium-Non-equilibrium Homogeneous or Heterogeneous Systems," NASA CR-1064, June 1968.

[8] Milos, F.S. and Chen, Y.-K., "Comprehensive Model for Multicomponent Ablation Thermochemistry," AIAA Paper 97-0141, Jan. 1997.

[9] McBride, B.J., and Gordon, S., "Computer Program for Calculation of Complex Chemical Equilibrium Compositions and Applications," NASA RP-1311, June 1996. 

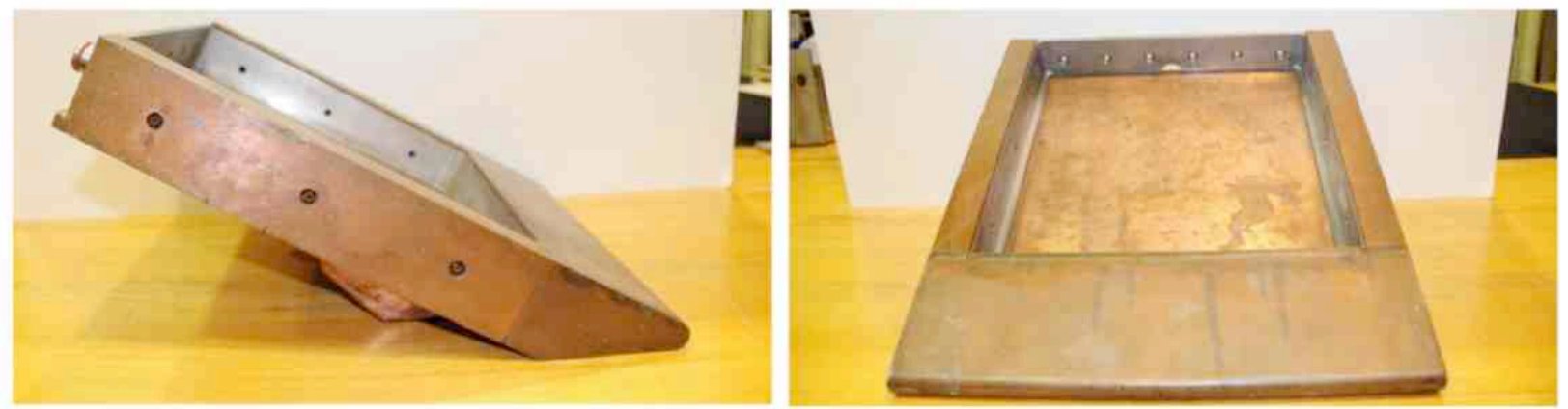

Figure 1. Arcjet test fixture with cavity to accommodate calibration and test specimens.

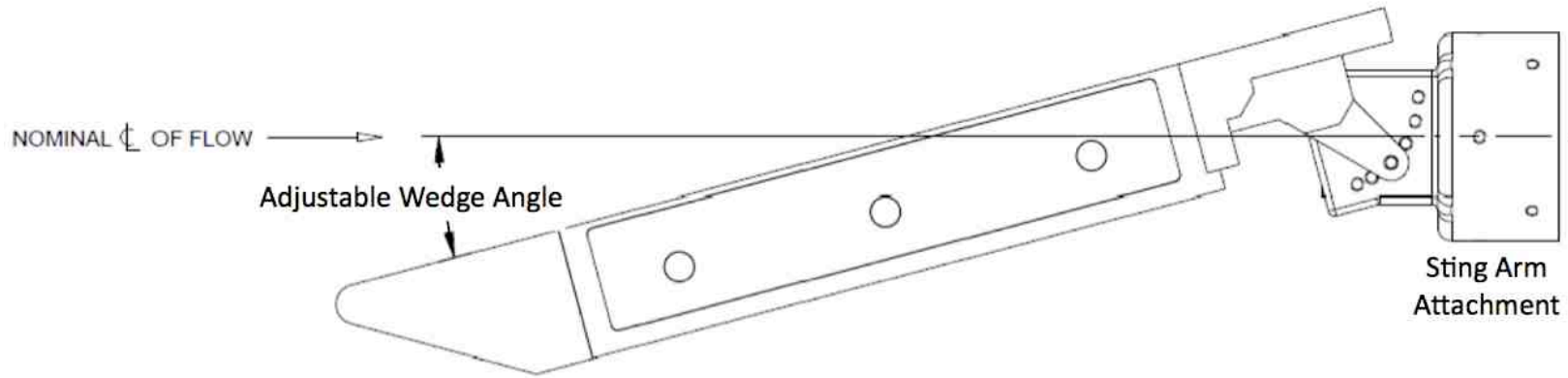

Figure 2. Wedge model insertion into conical arcjet flowfield. The sting-arm attachment is at the nozzle centerline.
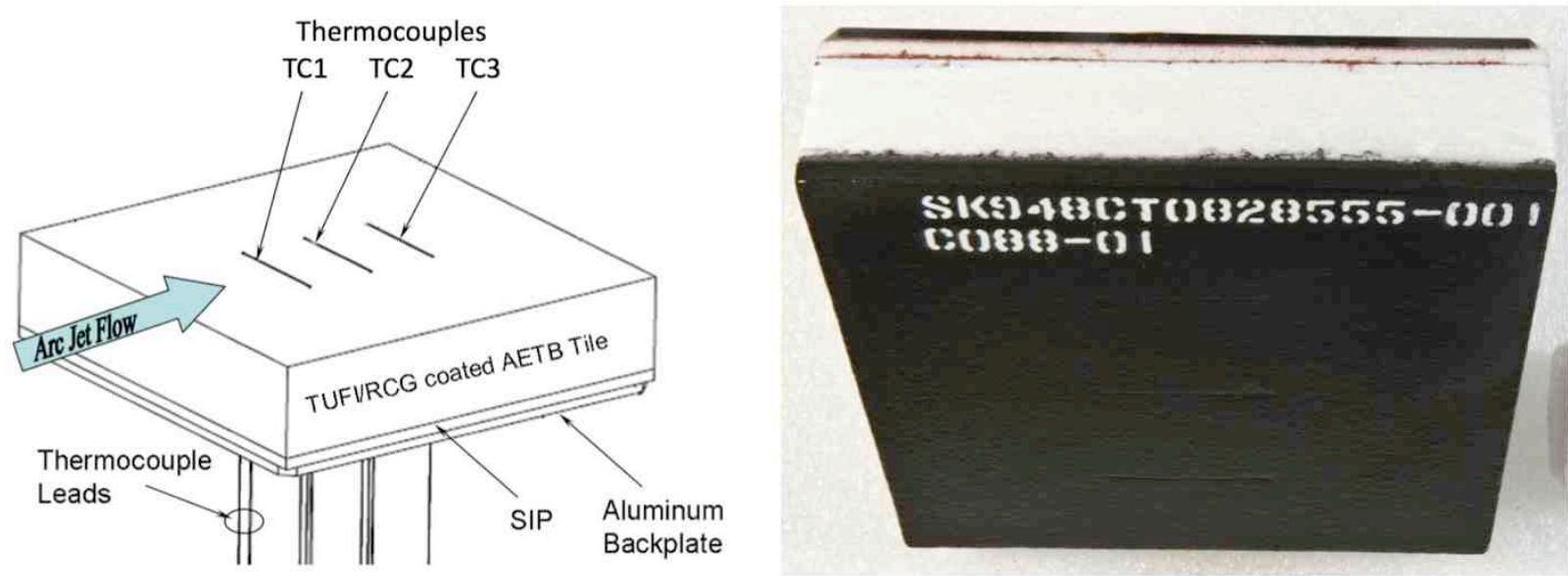

Figure 3. Diagram and photo of wedge calibration tile which is reusable. 

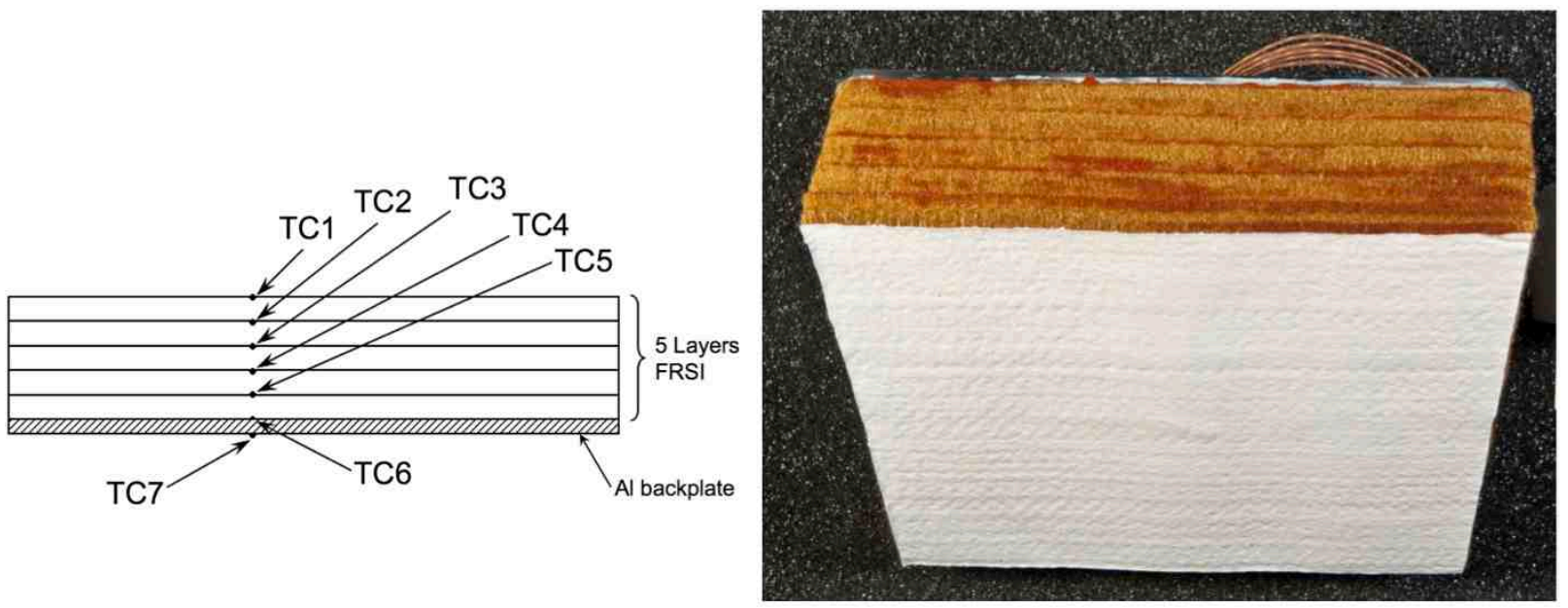

Figure 4. Diagram and pre-test photo of bonded multilayer FRSI test specimen.

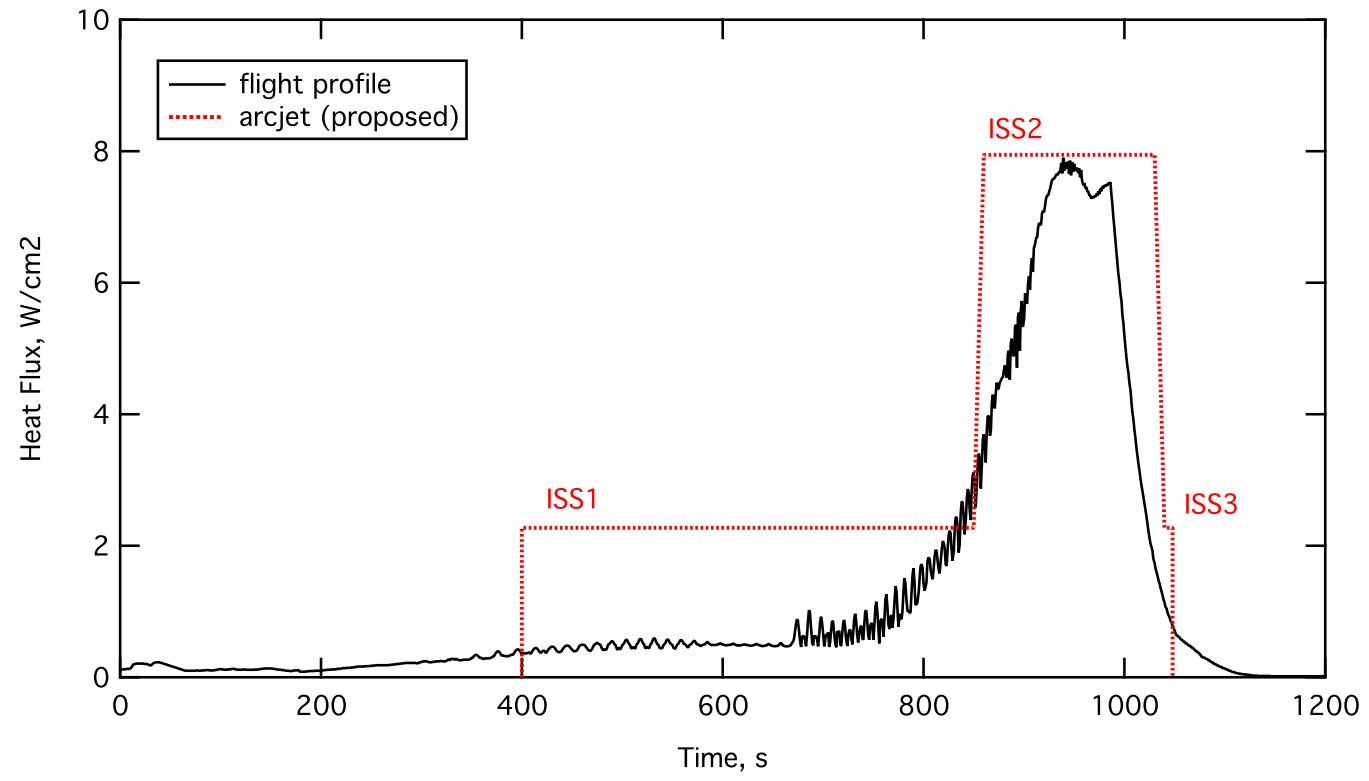

Figure 5a. ISS-return environment and proposed arcjet conditions for stepped profile test.

Condition ISS1 $=$ ISS3. 


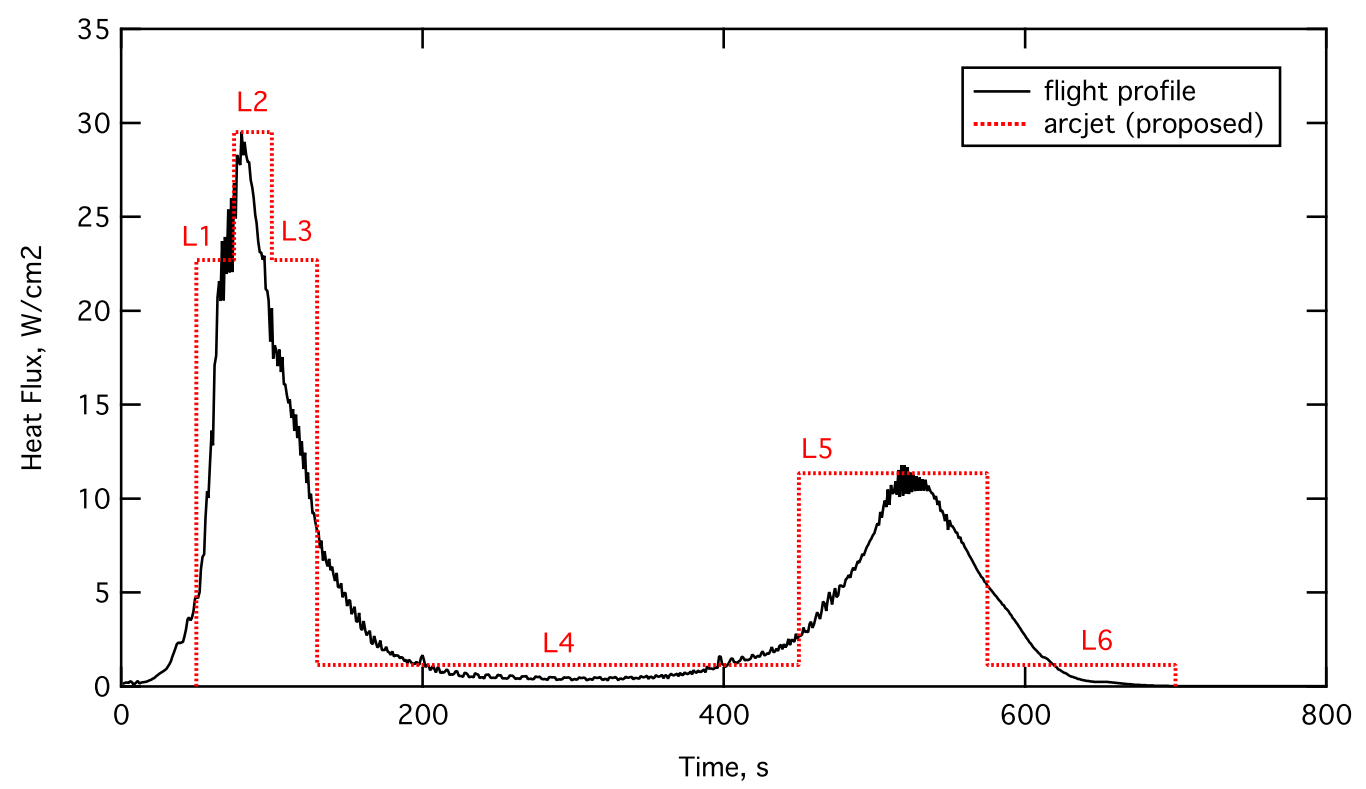

Figure 5b. Lunar-return environment and proposed arcjet conditions for stepped profile test. Conditions $\mathrm{L1}=\mathrm{L3}$ and $\mathrm{L} 4=\mathrm{L6}$.
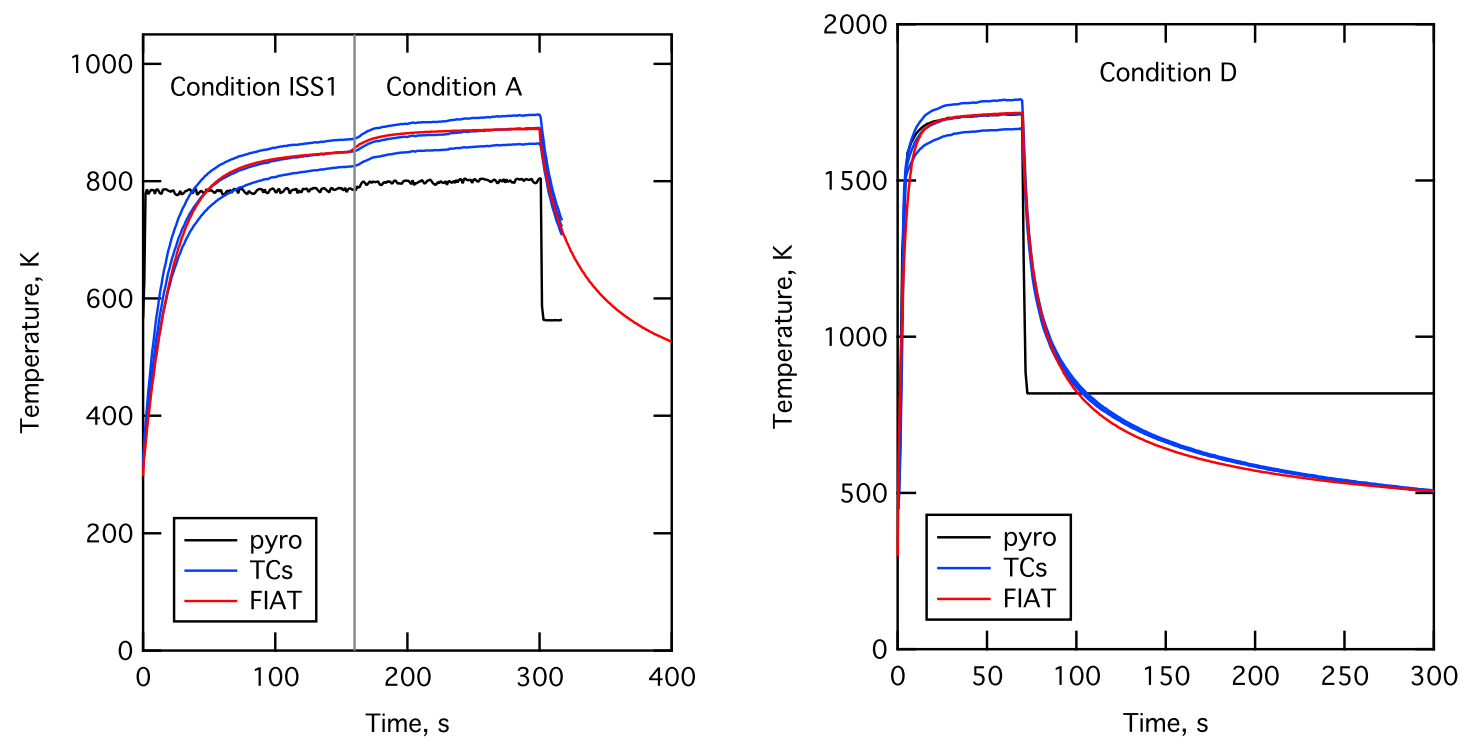

Figure 6. Surface temperature data and model predictions for calibration tile in two different arcjet runs. 

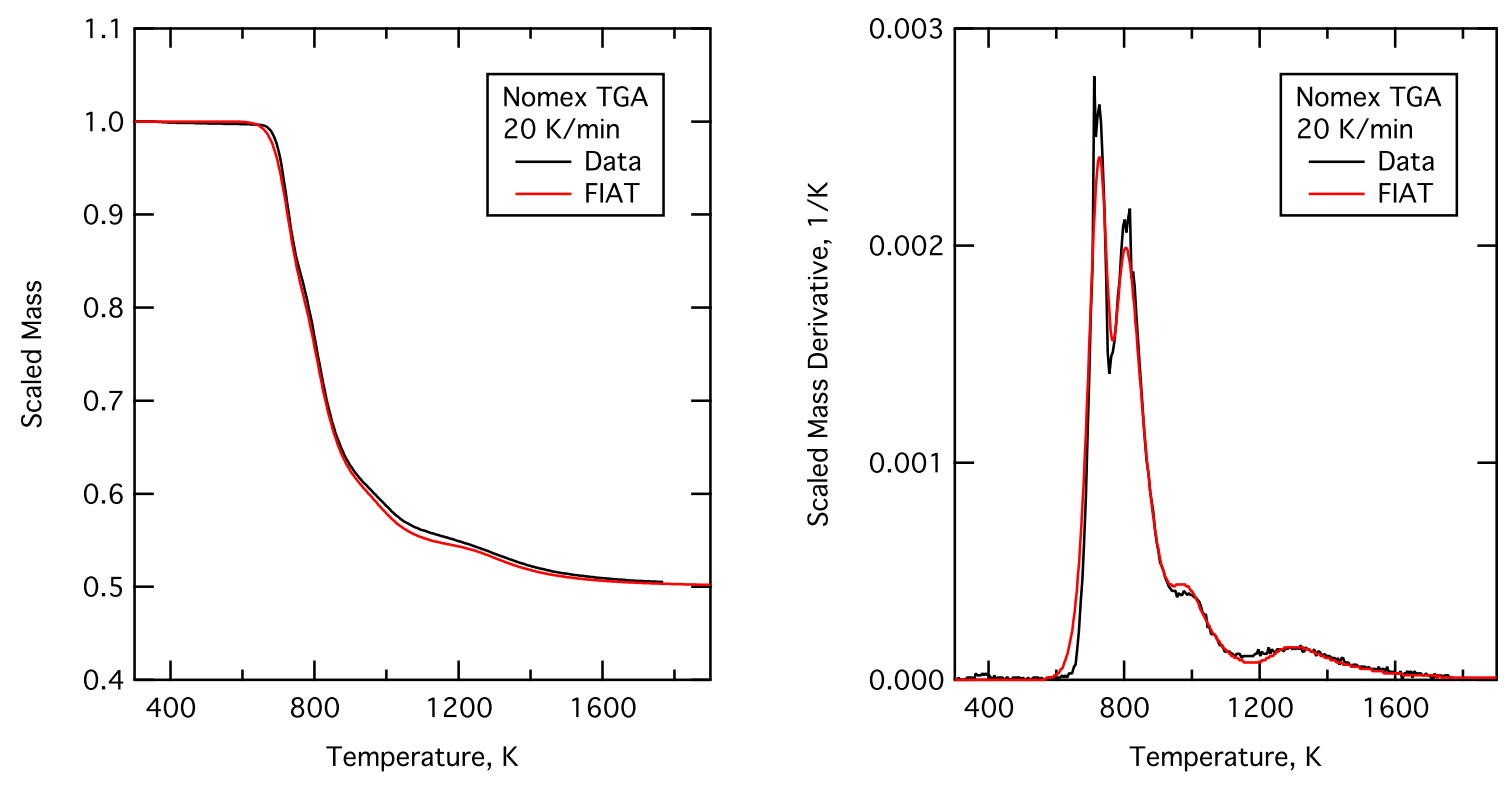

Figure 7. Data and model predictions for thermal decomposition of FRSI Nomex in an inert atmosphere.

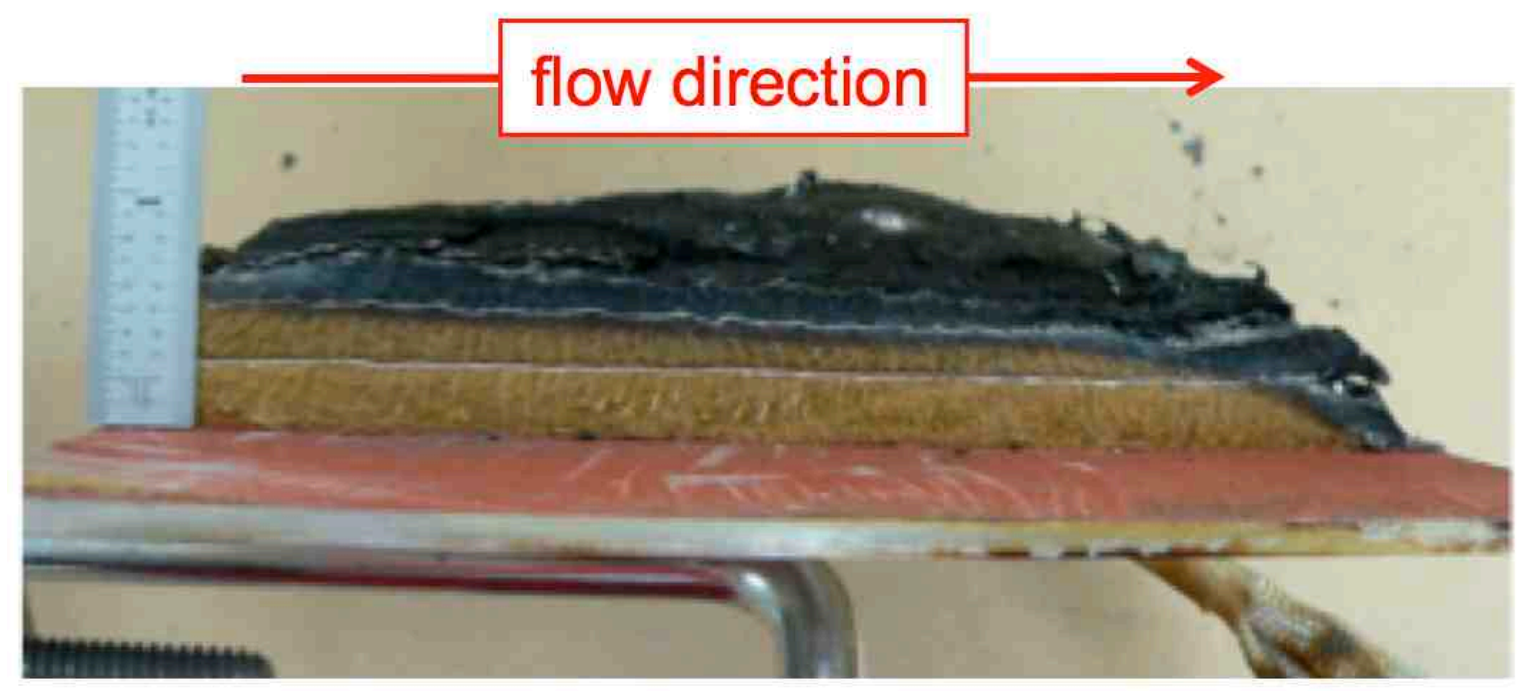

Figure 8. Cross section of sample 3029 shows thickness shrinkage and edge effects. 


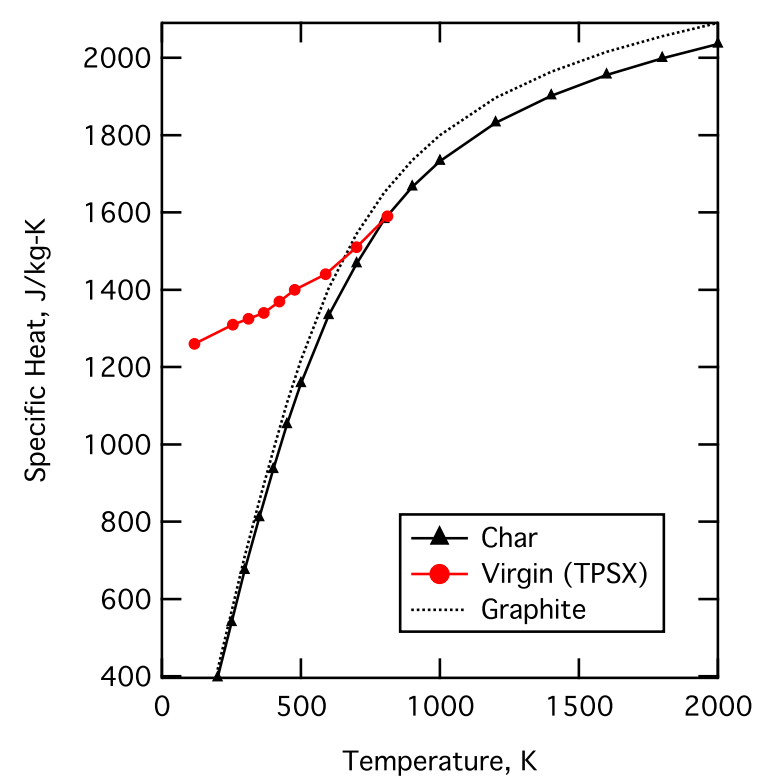

Figure 9. Specific heat of FRSI-Nomex model.

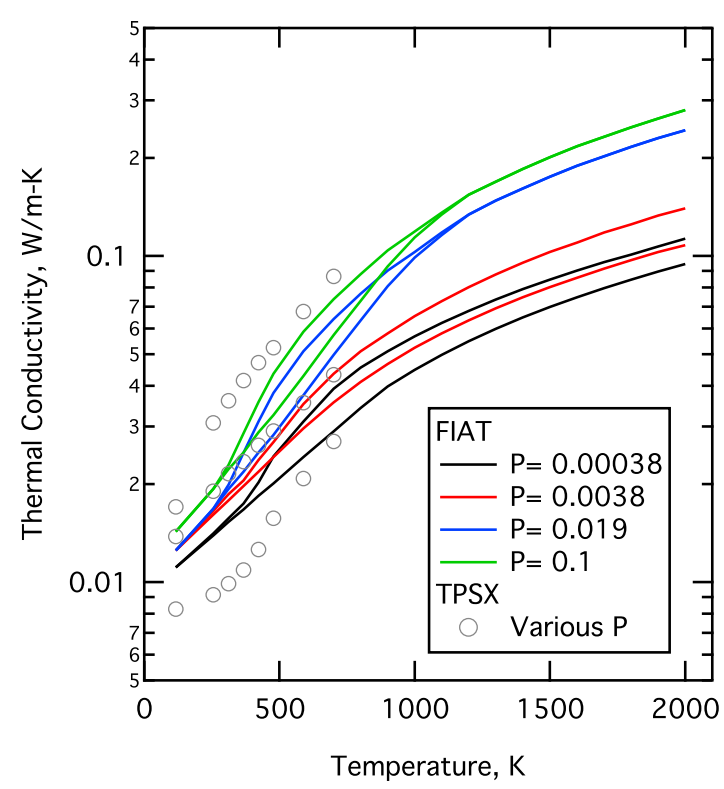

Figure 11. Thermal conductivity of FRSI-Nomex model.

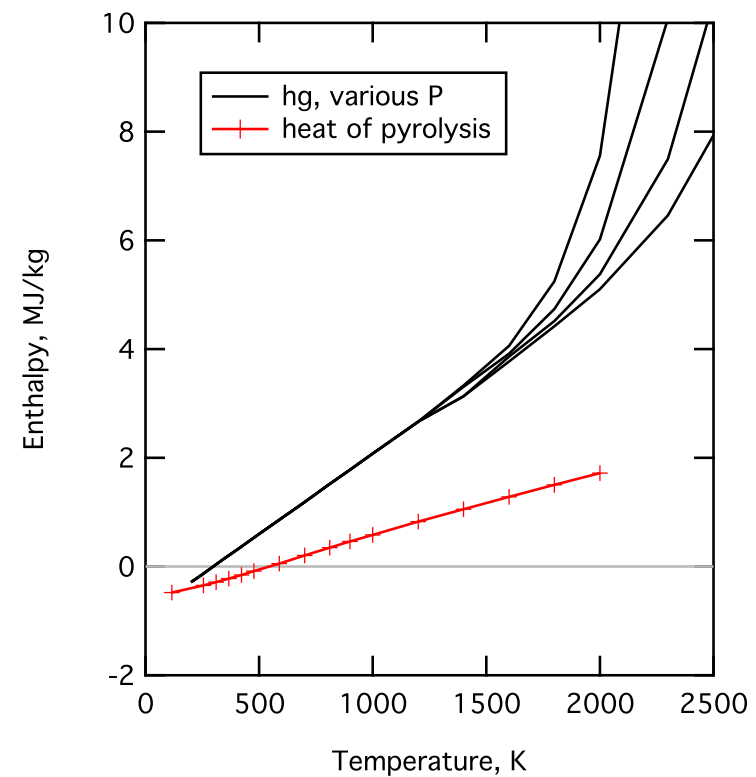

Figure 10. Pyrolysis gas enthalpy and heat of pyrolysis.

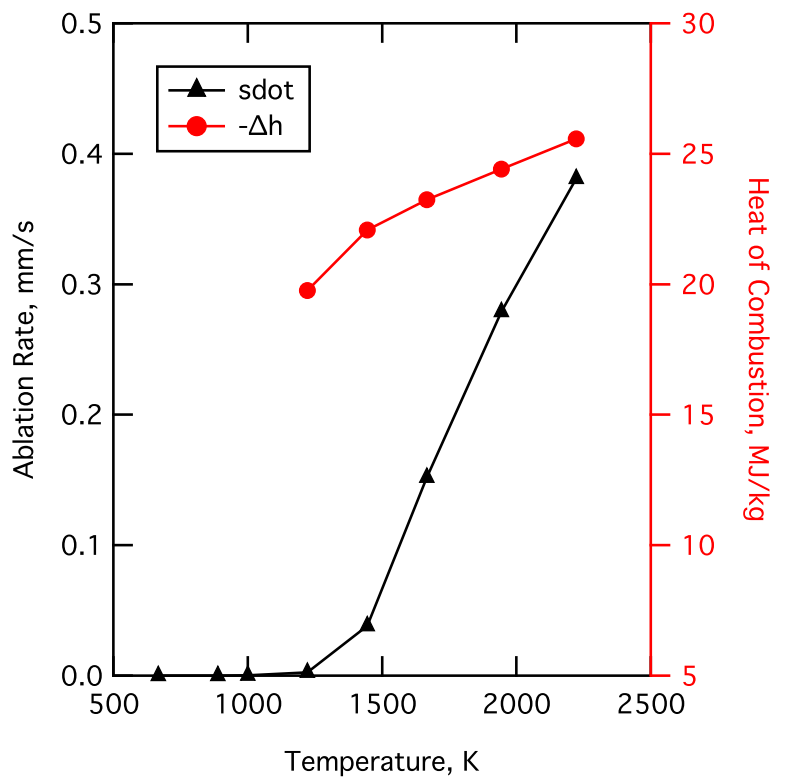

Figure 12. Ablation quantities of FRSI-Nomex model. The heat of combustion is $-\Delta h$. 


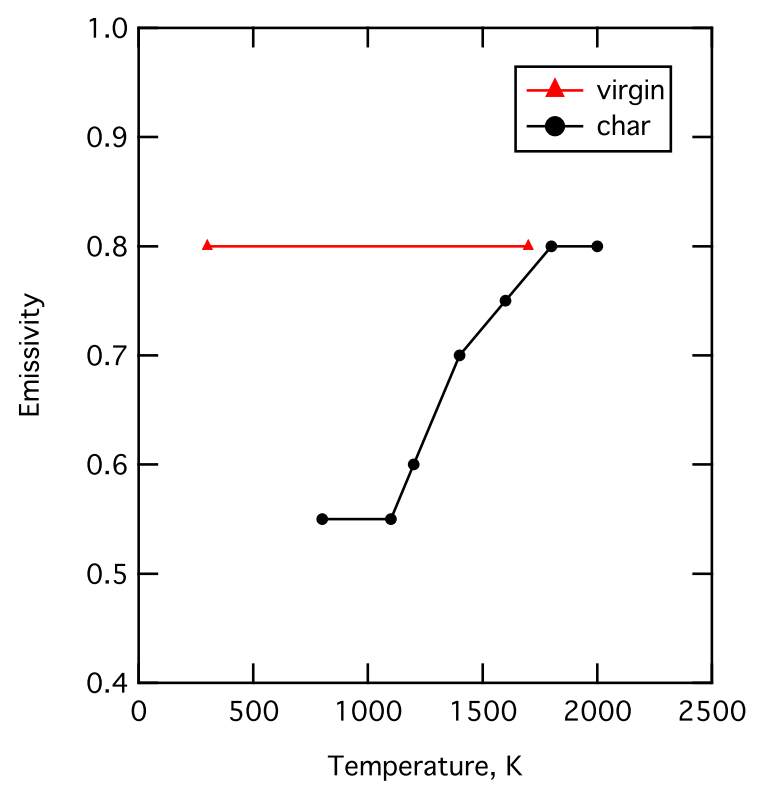

Figure 13. Emissivity of FRSI-Nomex model.
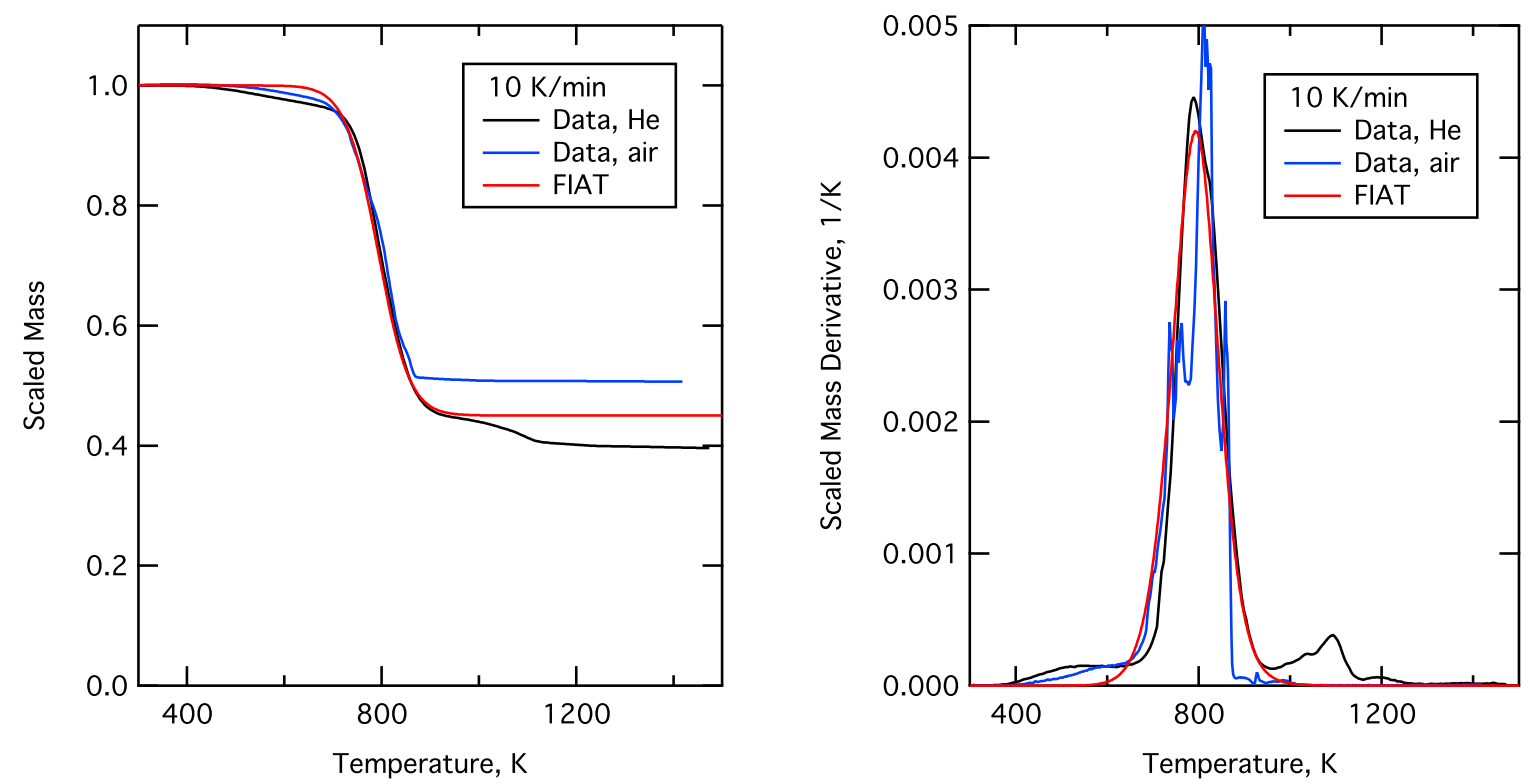

Figure 14. Data and model predictions for thermal decomposition of RTV-560. 


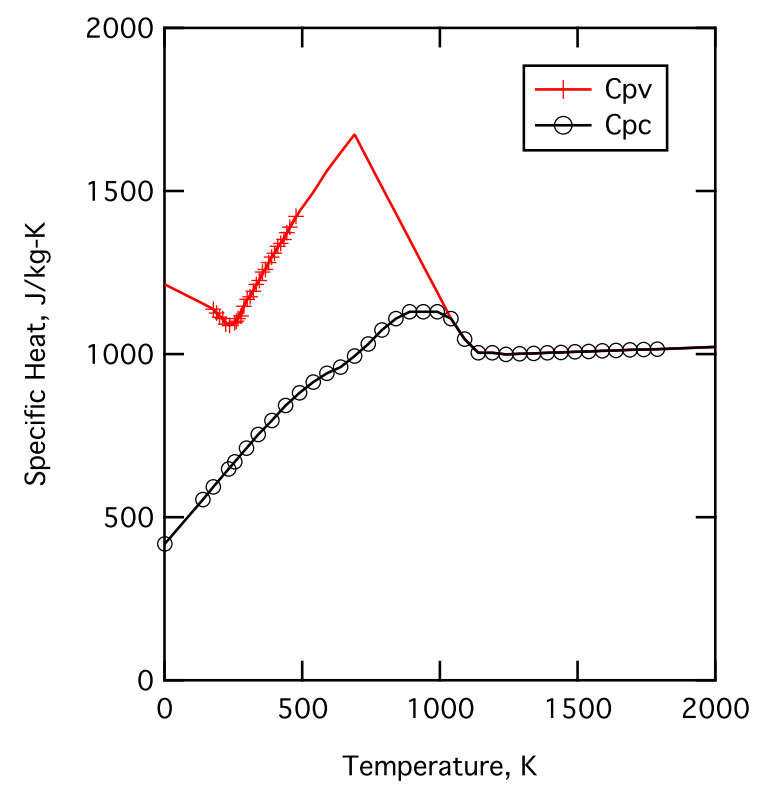

Figure 15. Specific heat of FRSI-RTV model.

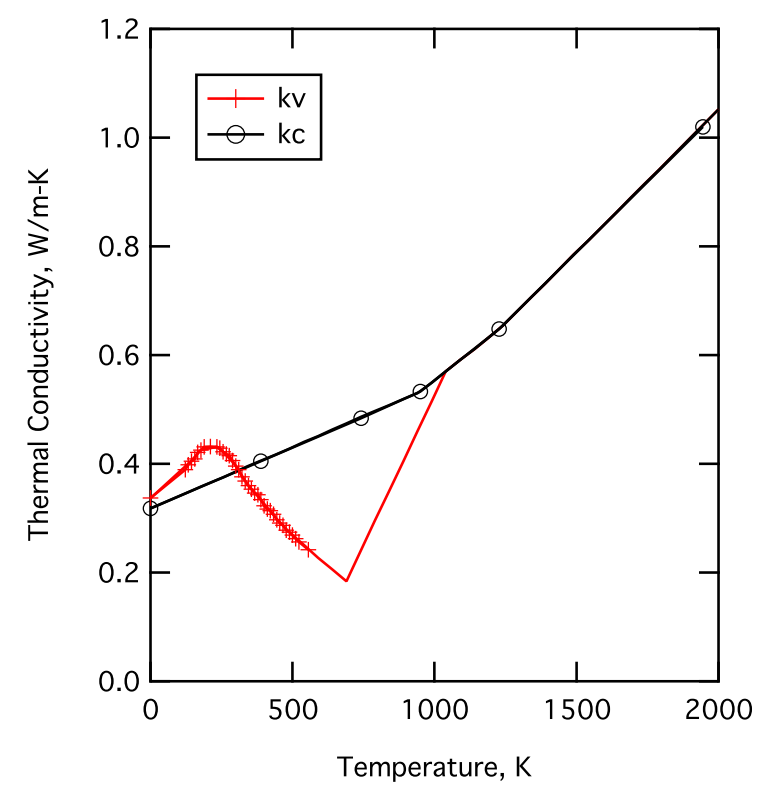

Figure 16. Thermal conductivity of FRSI-RTV model.
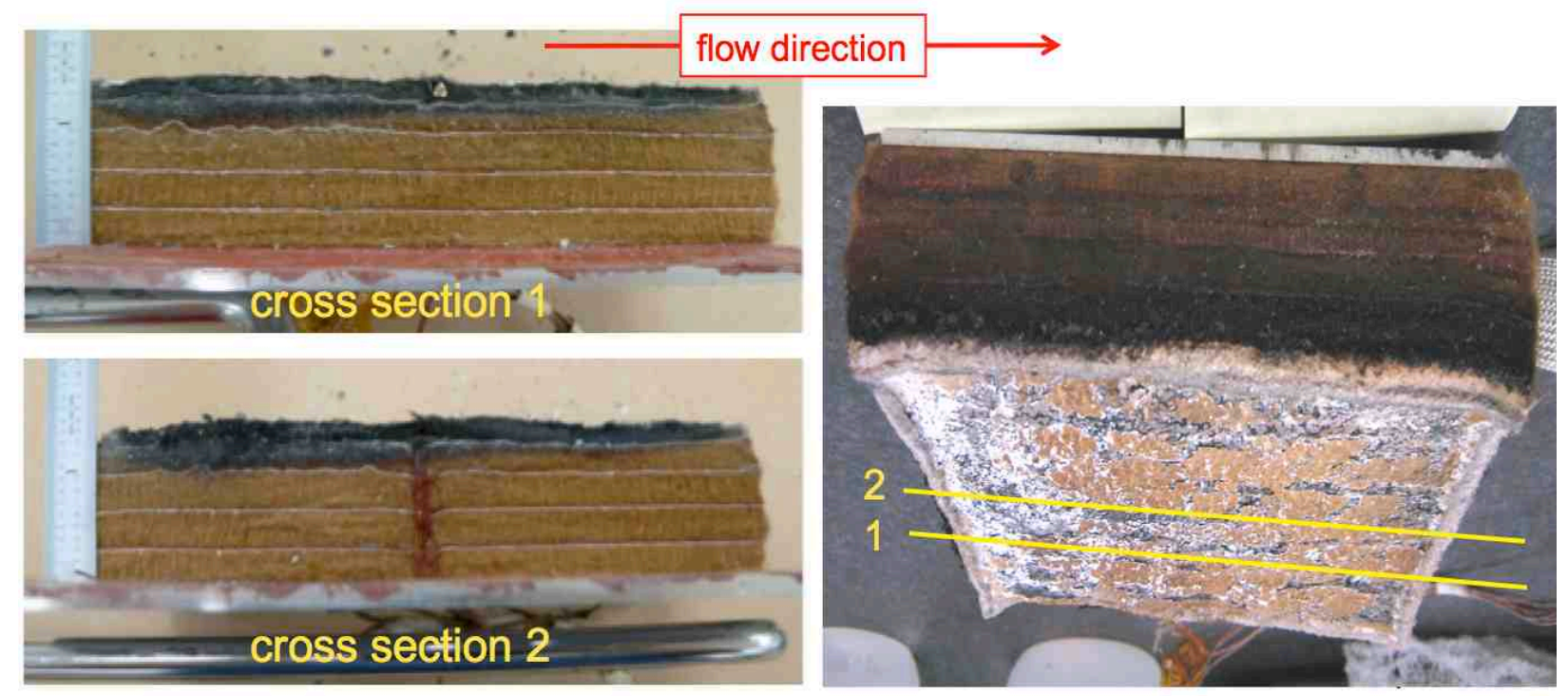

Figure 17a. Post-test cross sections and oblique view of sample 3033 tested at condition A for 900 seconds. 

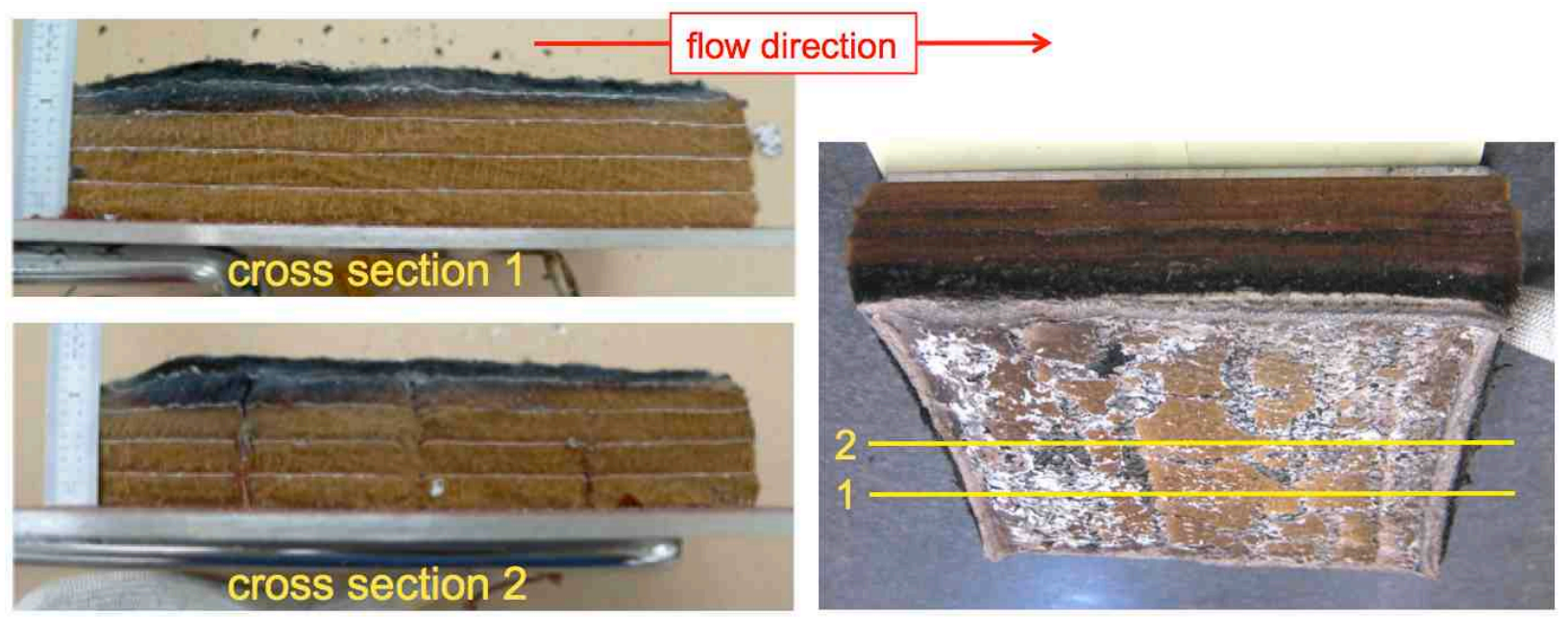

Figure 17b. Post-test cross sections and oblique view of sample 3032 tested at condition A for 970 seconds.

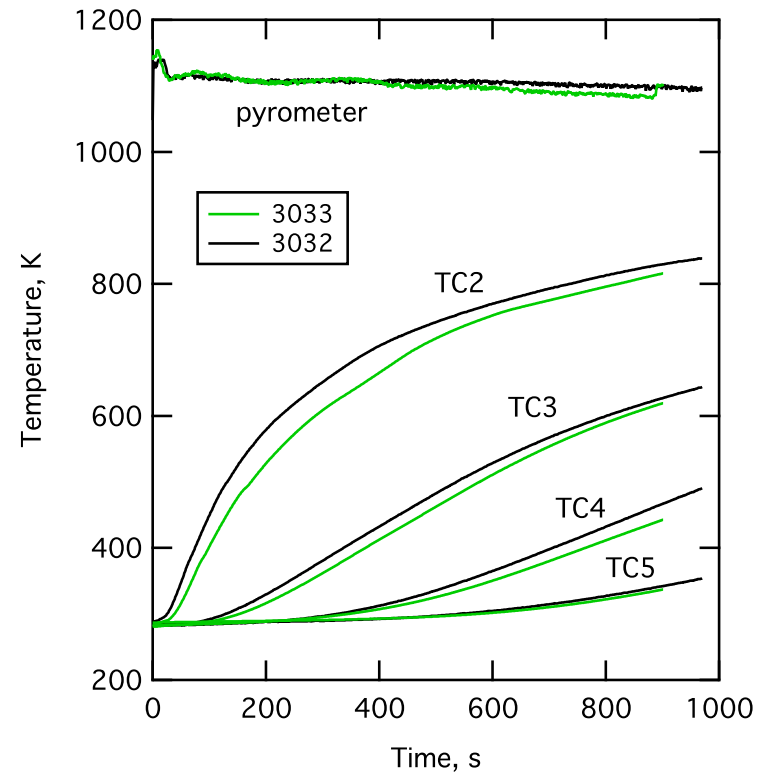

Figure 18. Comparison of data for two samples tested at condition A.

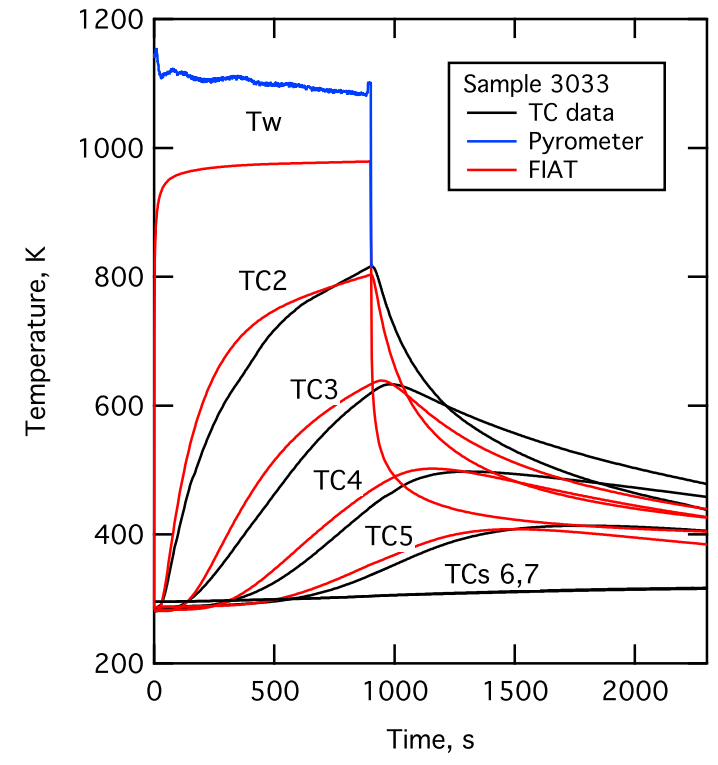

Figure 19a. Data and predictions for surface and in-depth temperatures of sample 3033. 


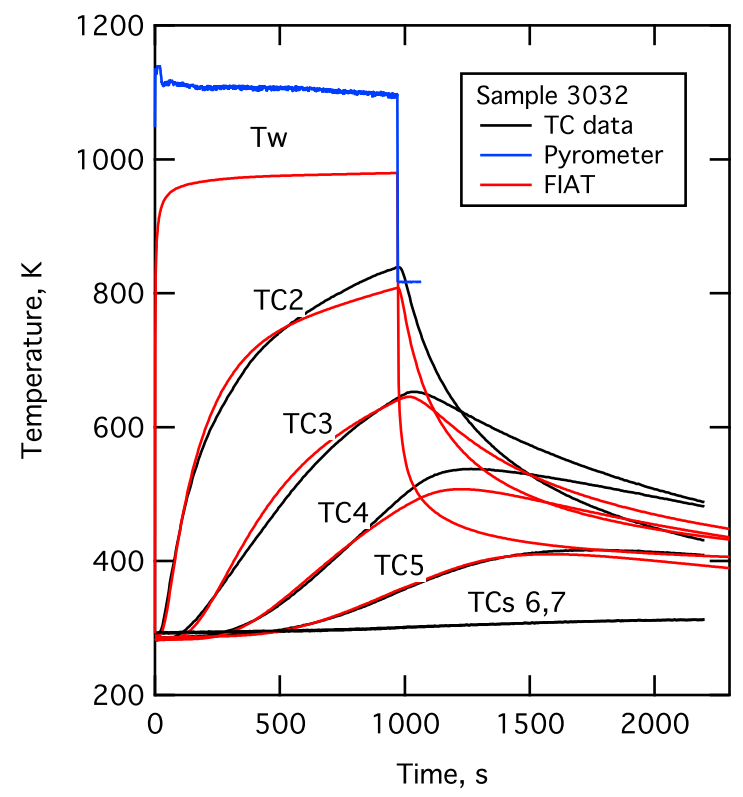

Figure 19b. Data and predictions for surface and in-depth temperatures of sample 3032.
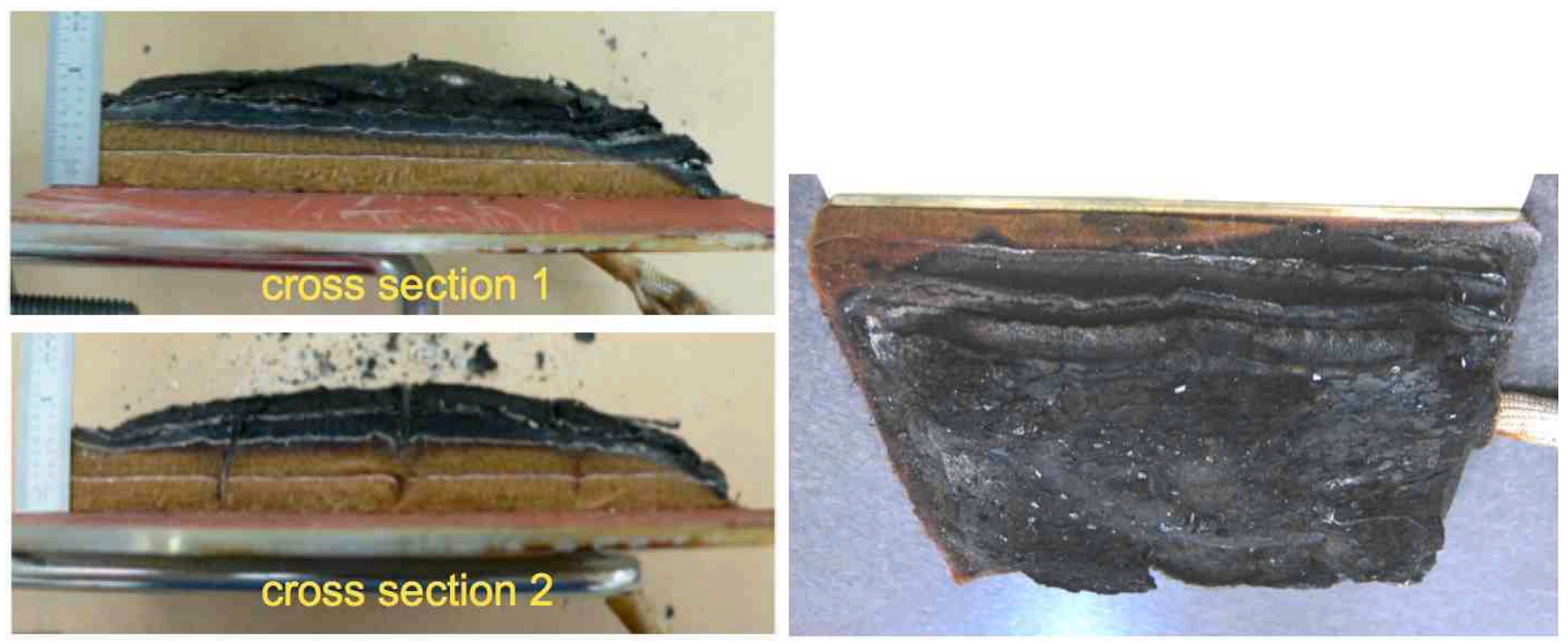

Figure 21. Post-test cross sections and oblique view of sample 3029 tested at condition $B$ for 600 seconds. During cooldown, a large piece of char detached from the upper section of the oblique view (not in cross sections). 


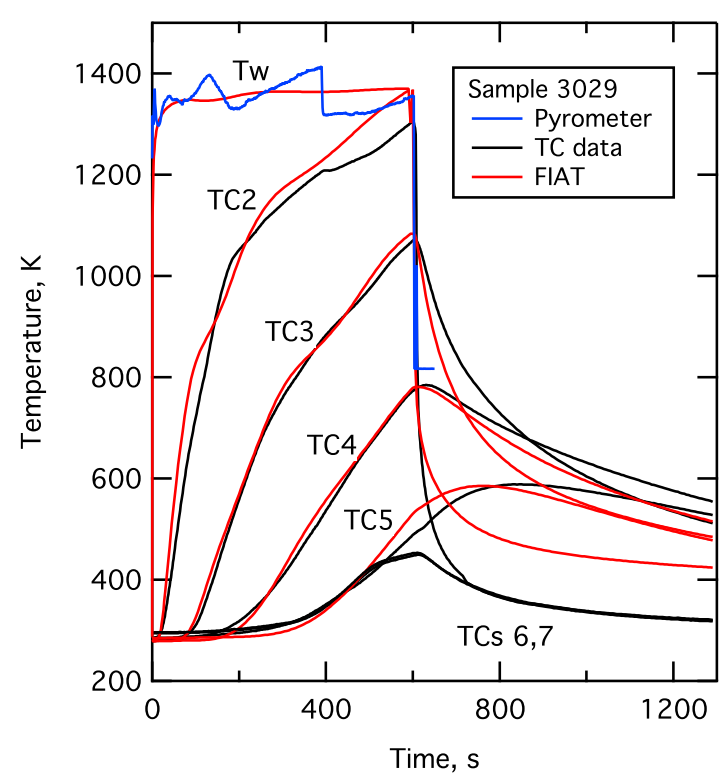

Figure 22. Data and predictions for surface and in-depth temperatures of sample 3029.

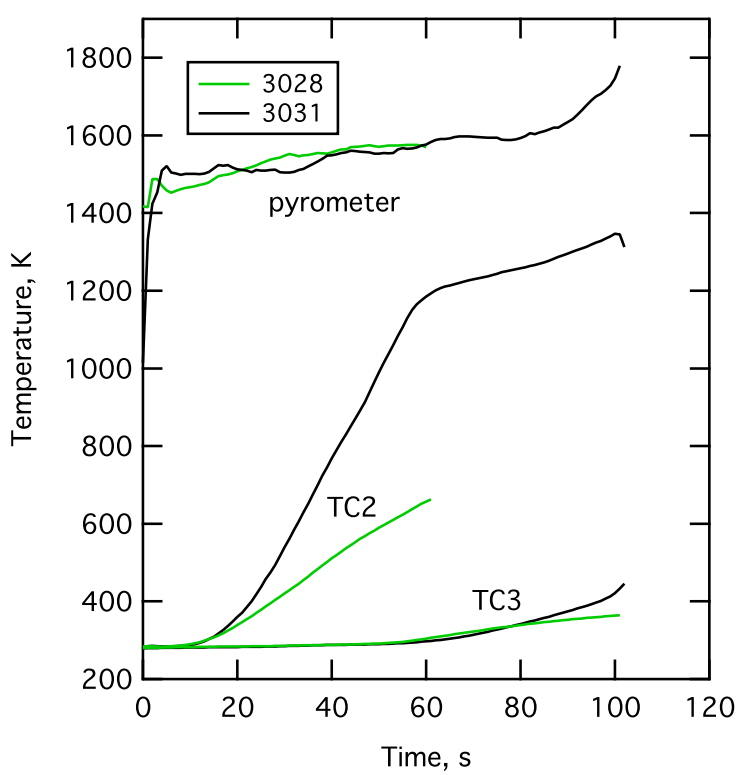

Figure 23. Comparison of data for two samples tested at condition $\mathbf{C}$.
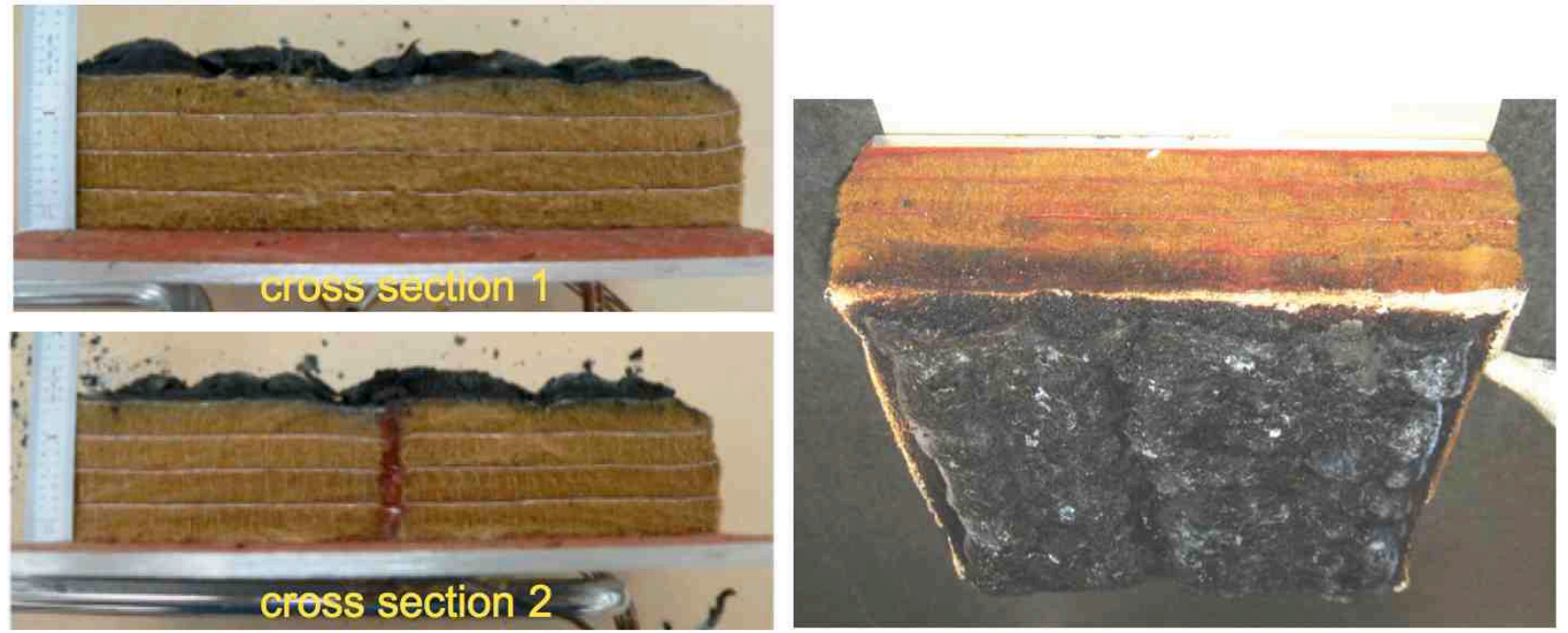

Figure 24a. Post-test cross sections and oblique view of sample 3028 tested at condition $\mathrm{C}$ for 60 seconds. 

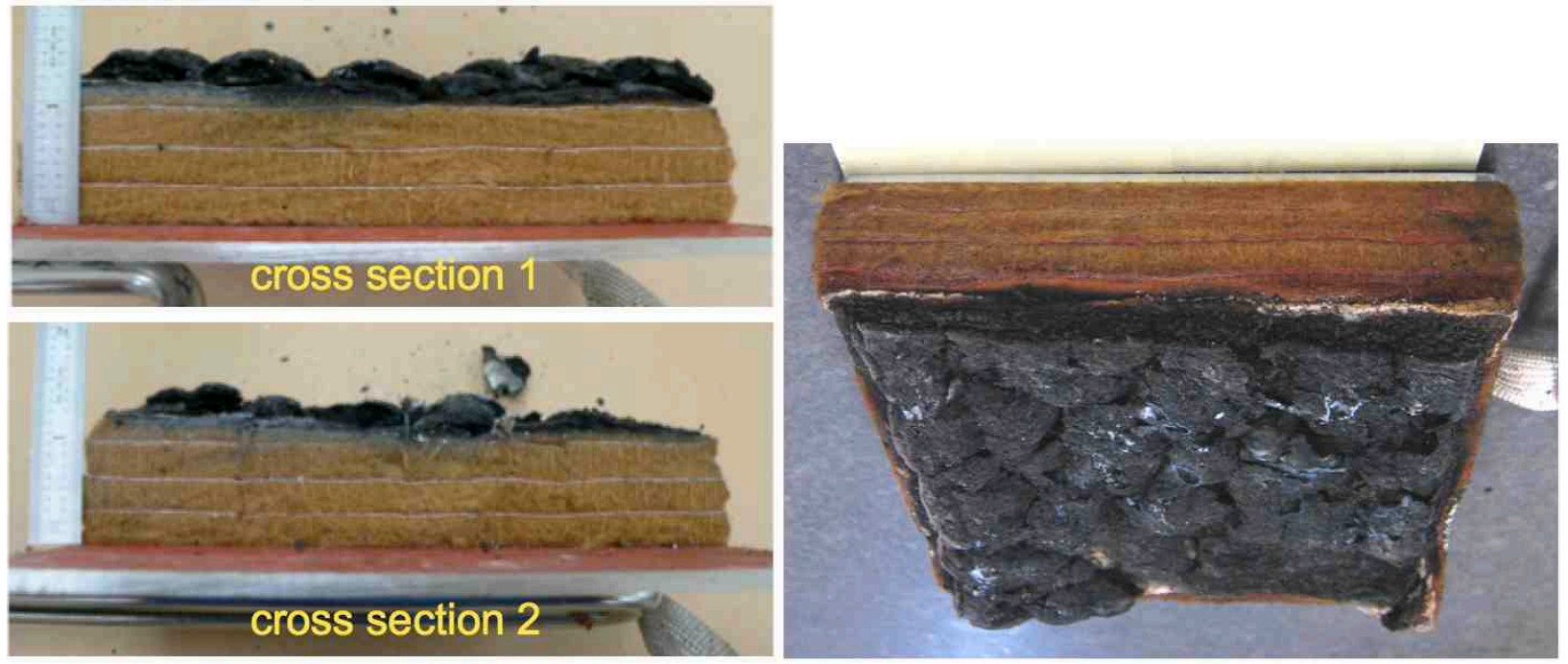

Figure 24b. Post-test cross sections and oblique view of sample 3031 tested at condition $\mathrm{C}$ for 100 seconds.

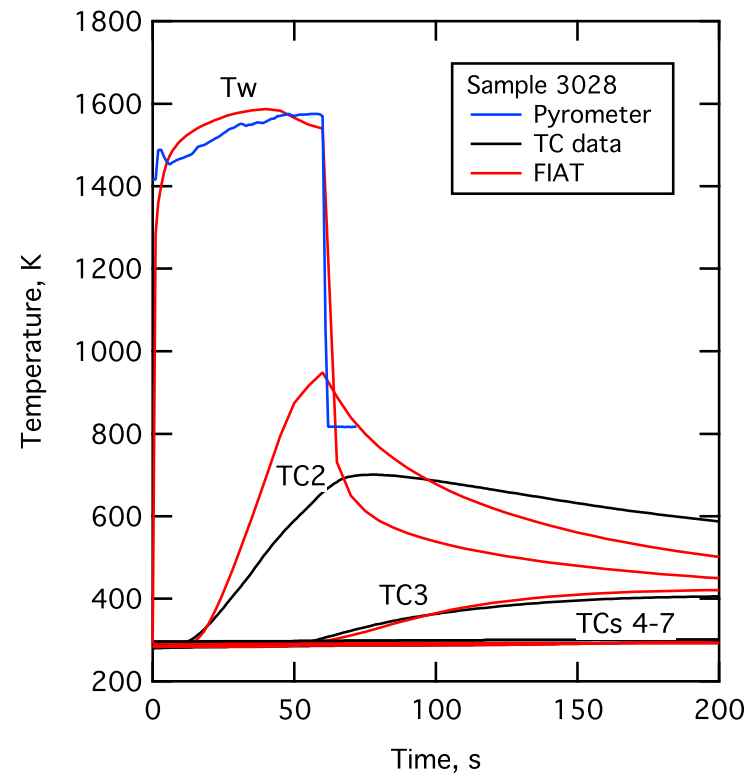

Figure 25a. Data and predictions for surface and indepth temperatures of sample 3028.

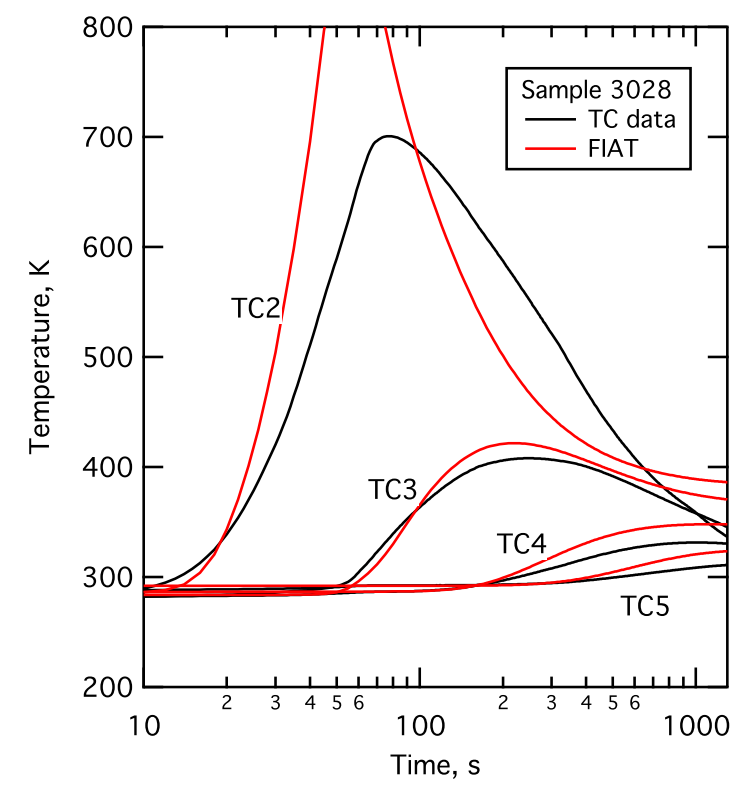

Figure 25b. Data and predictions for in-depth temperatures of sample $3028 \mathrm{on} \log$ time scale. 


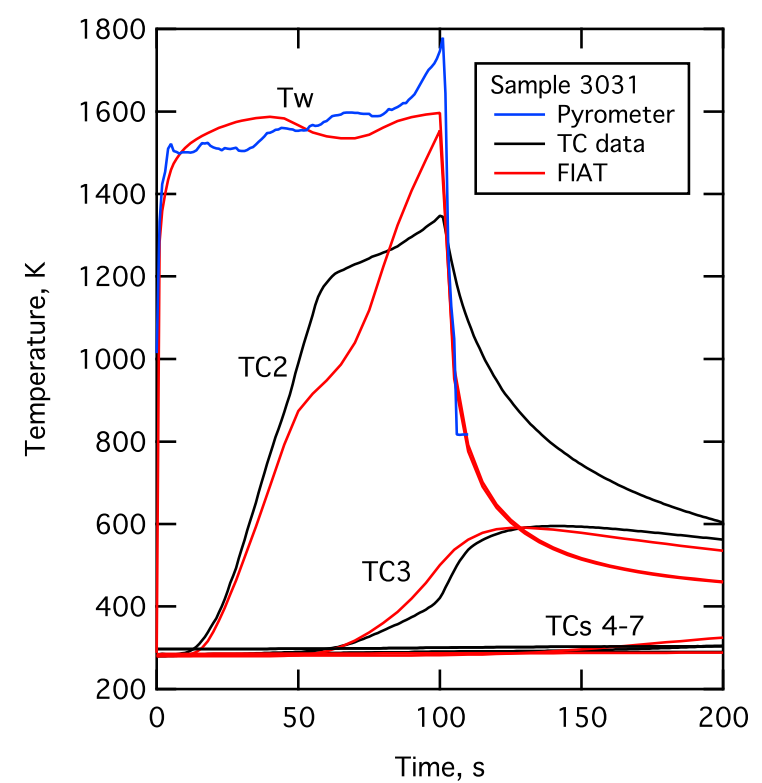

Figure 26a. Data and predictions for surface and indepth temperatures of sample 3031 .

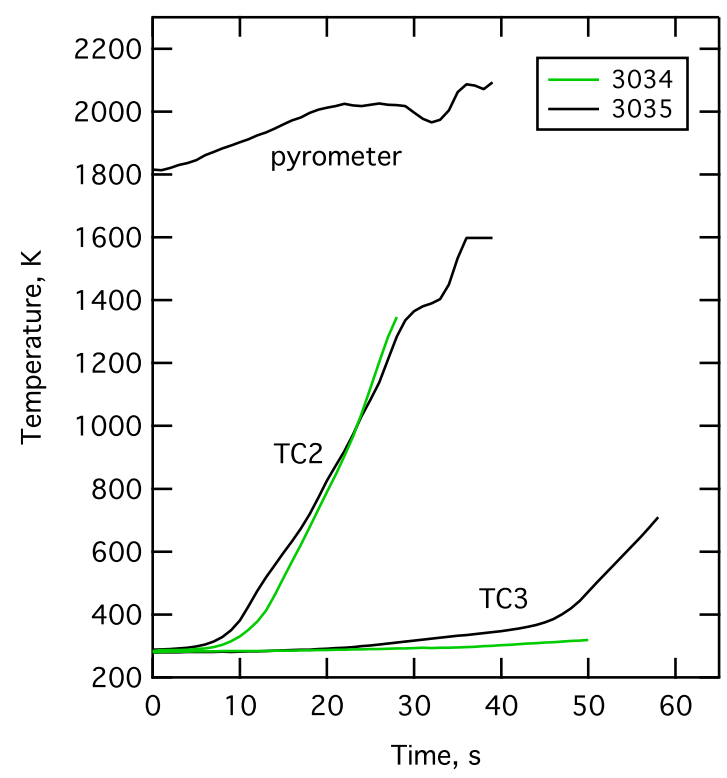

Figure 27. Comparison of data for two samples tested at condition D. No pyrometer data for sample 3032 .

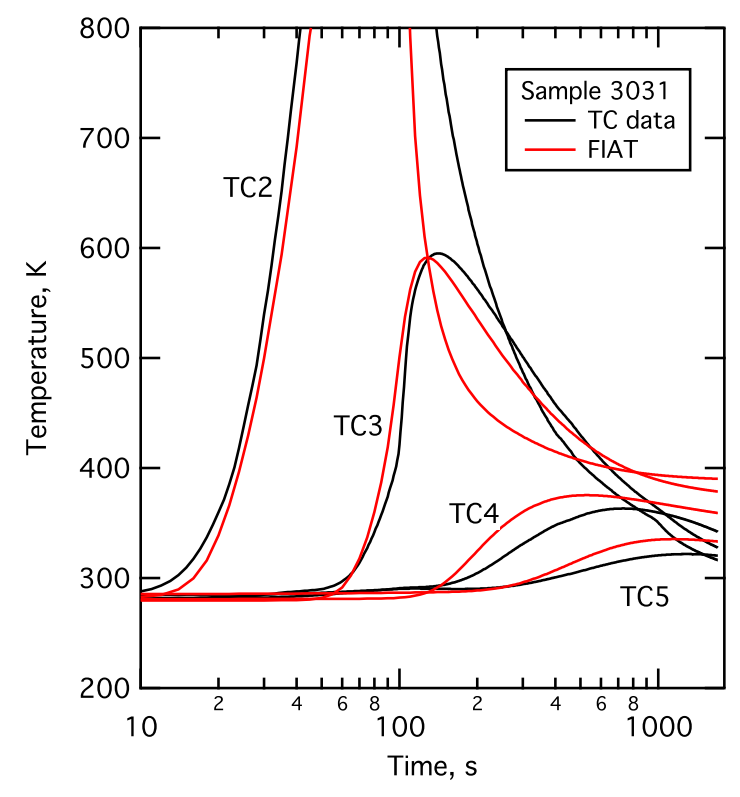

Figure 26b. Data and predictions for in-depth temperatures of sample 3031 on log time scale. 

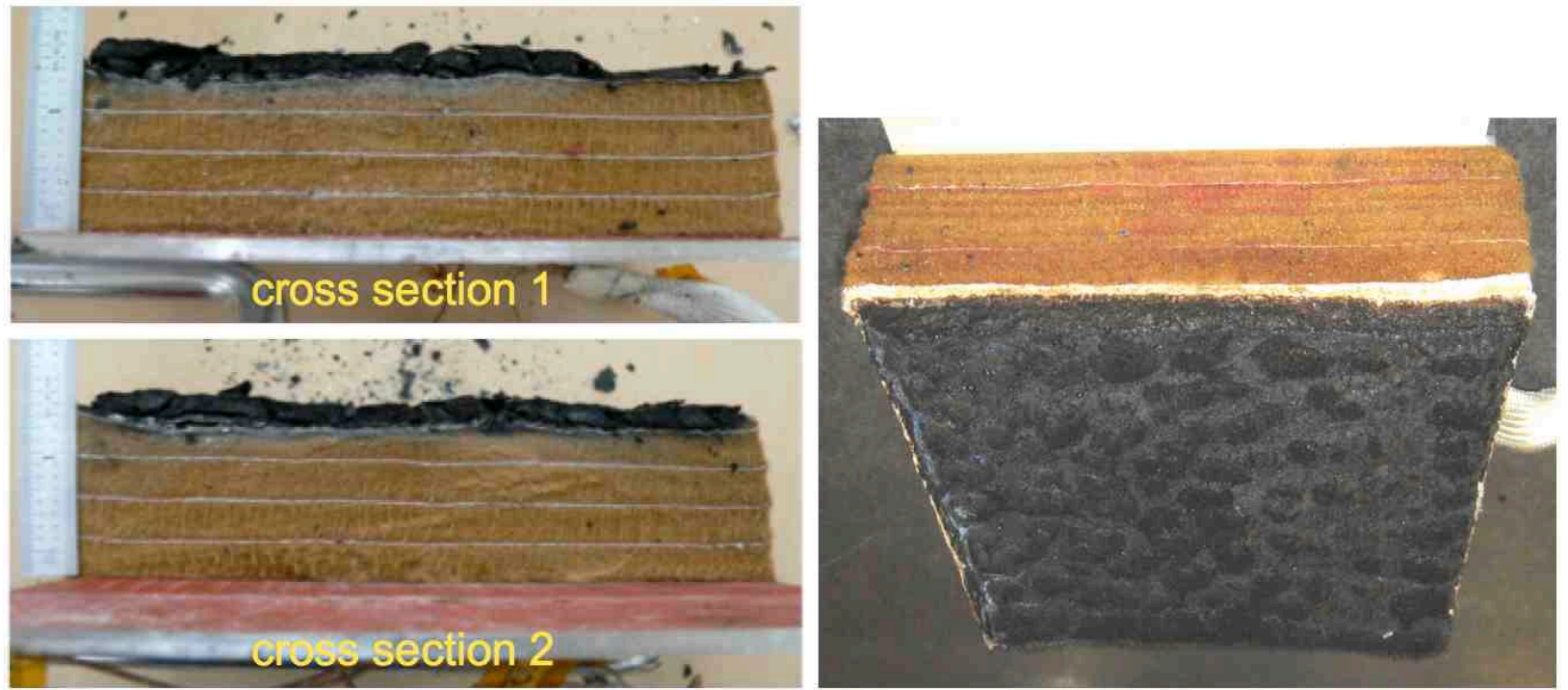

Figure 28a. Post-test cross sections and oblique view of sample 3034 tested at condition D for 28 seconds.
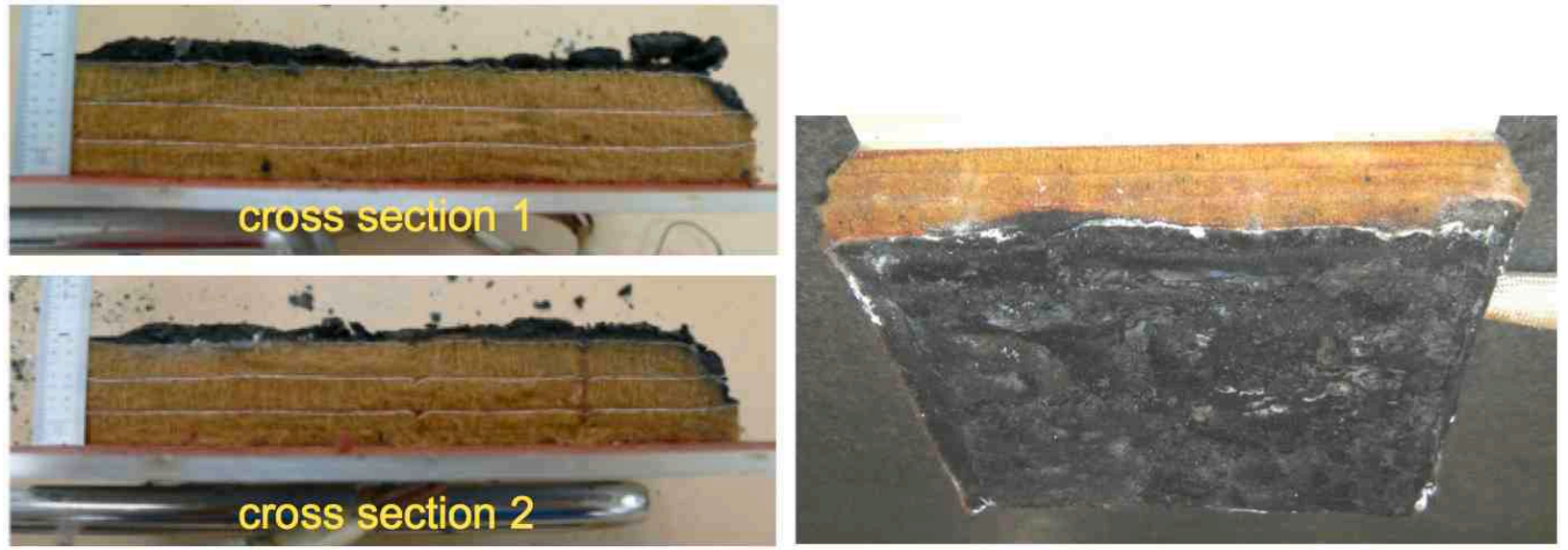

Figure 28b. Post-test cross sections and oblique view of sample 3035 tested at condition D for 58 seconds. 


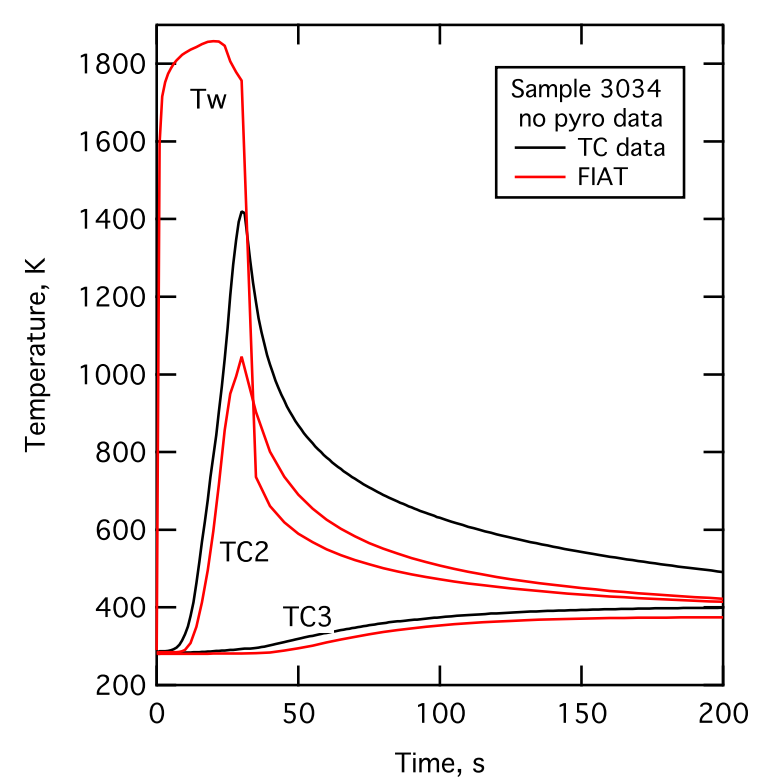

Figure 29a. Data and predictions for surface and indepth temperatures of sample 3034 .

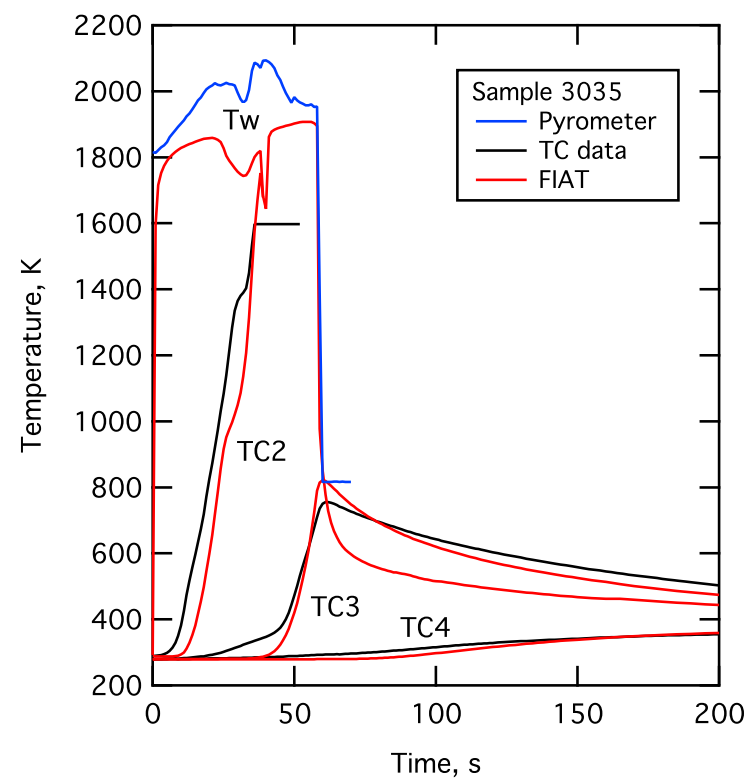

Figure 30a. Data and predictions for surface and indepth temperatures of sample 3035.

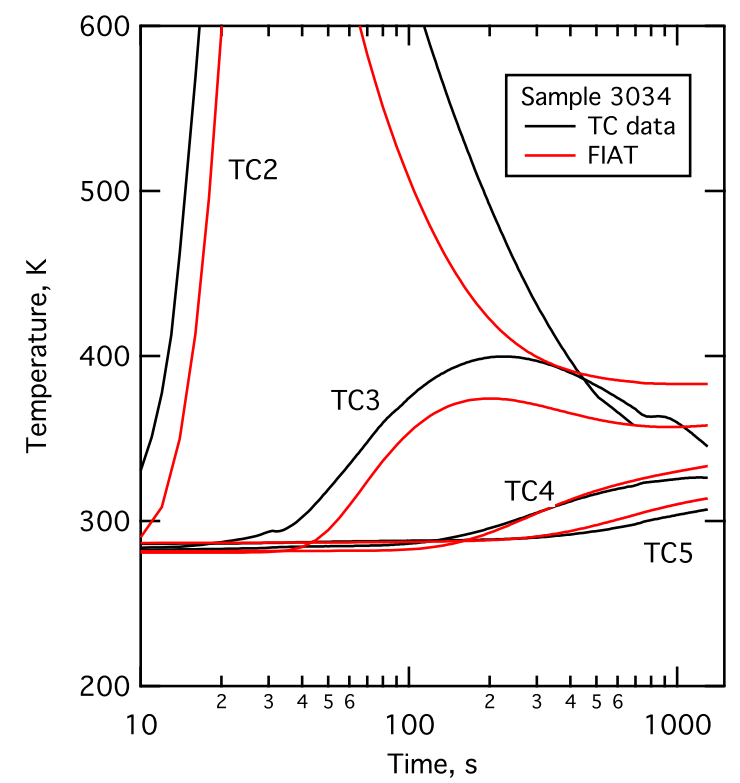

Figure 29b. Data and predictions for in-depth temperatures of sample 3034 on log time scale.

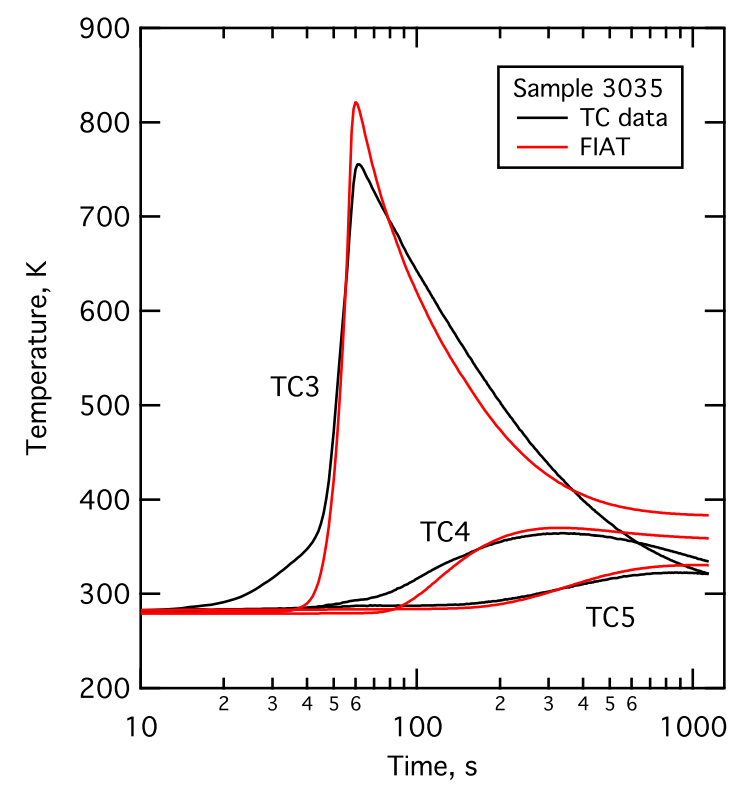

Figure 30b. Data and predictions for in-depth temperatures of sample 3035 on log time scale. 

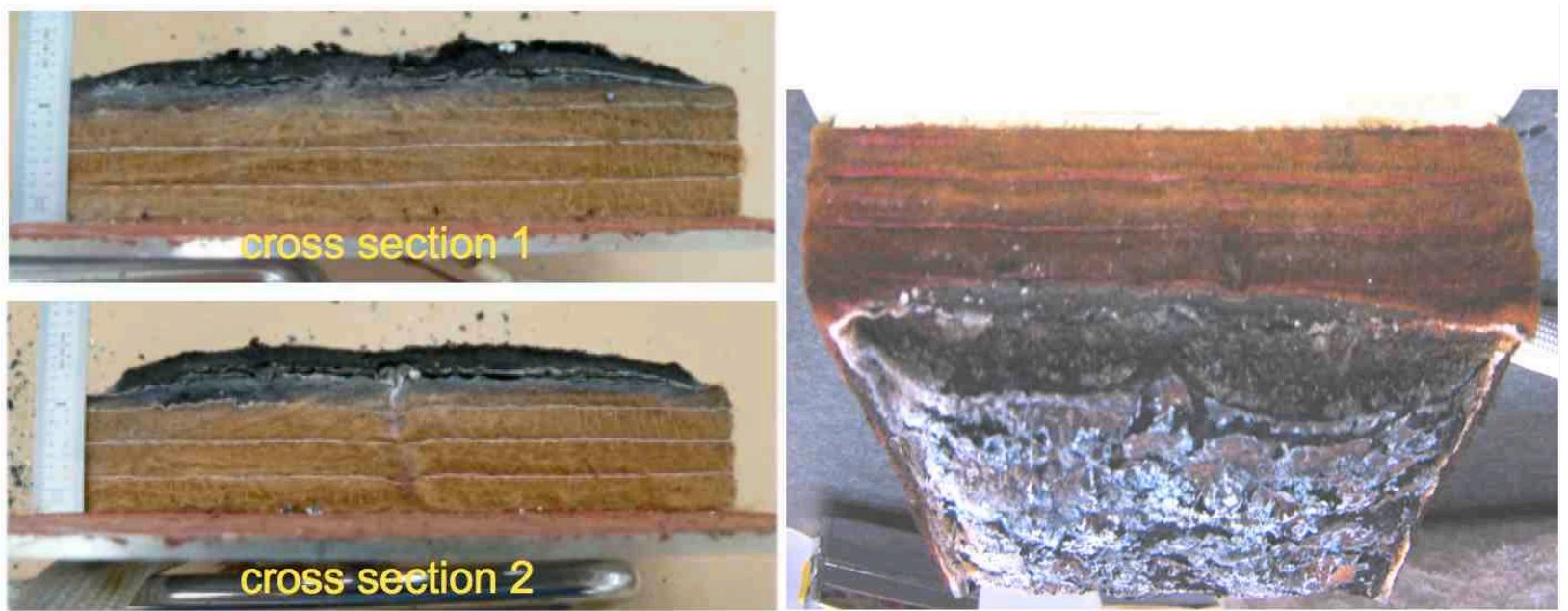

Figure 31. Post-test cross sections and oblique view of sample 3036 tested at ISS-return stepped profile.

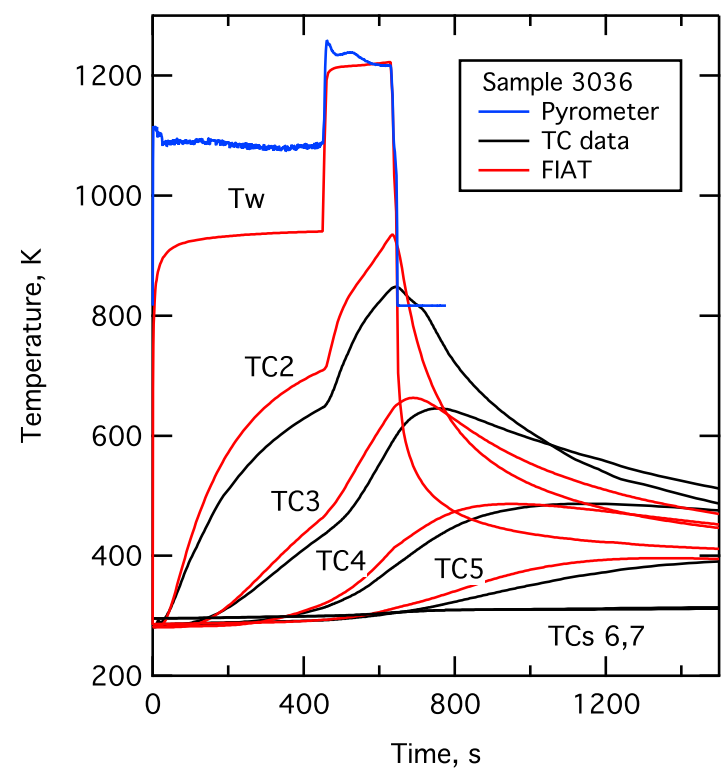

Figure 32a. Data and predictions for surface and indepth temperatures of sample 3036 .

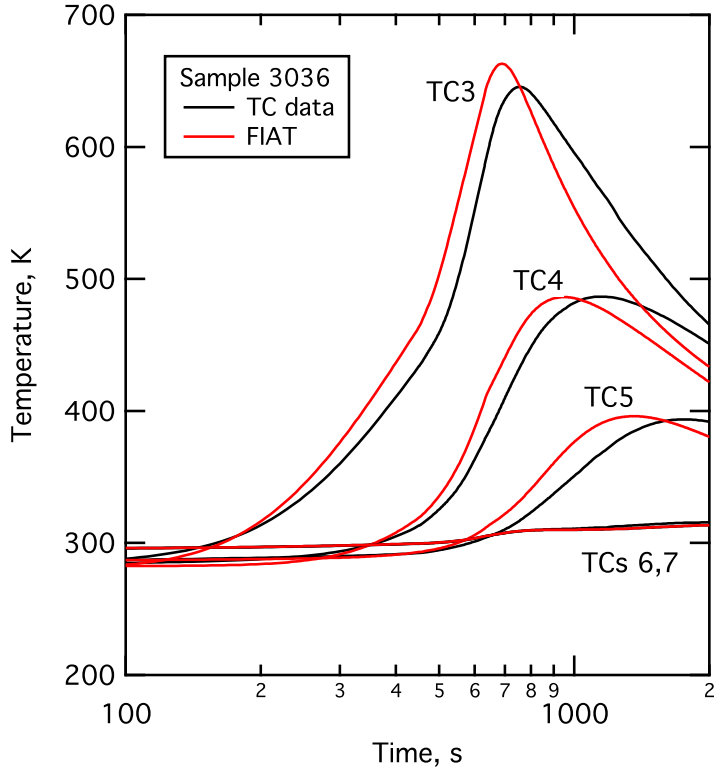

Figure 32b. Data and predictions for in-depth temperatures of sample 3036 on log time scale. 

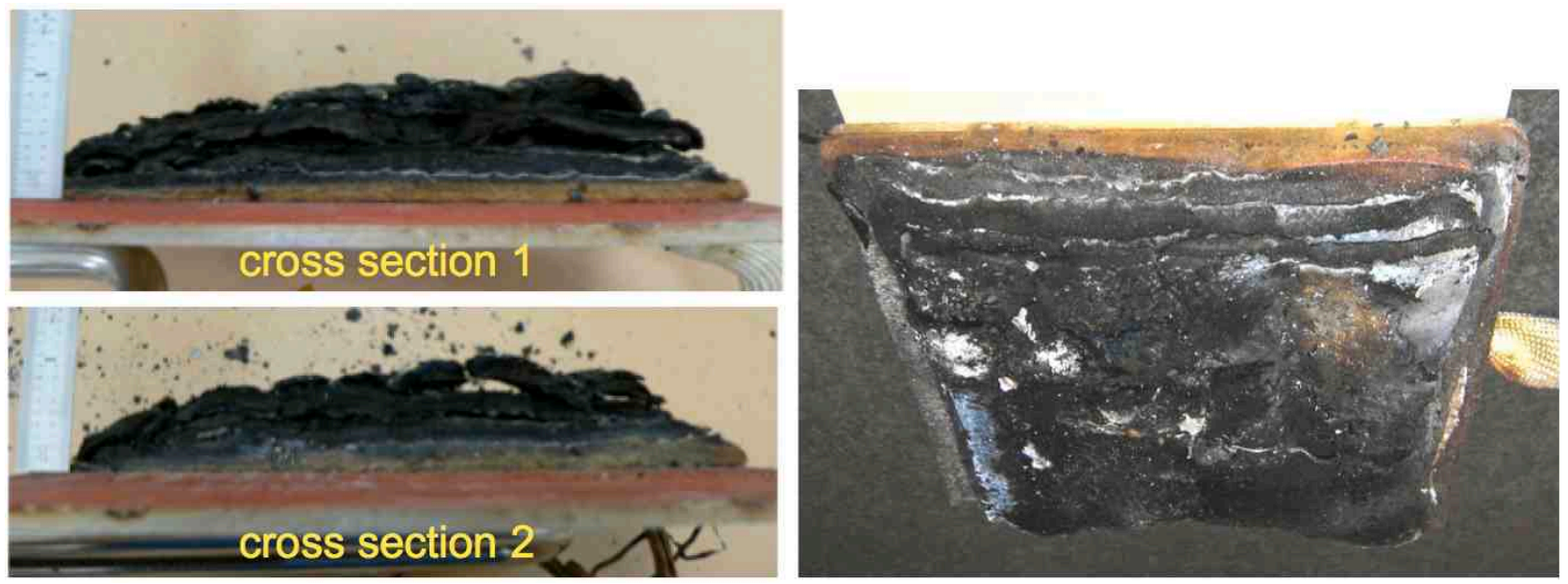

Figure 33. Post-test cross sections and oblique view of sample 3037 tested in Lunar-return stepped profile.

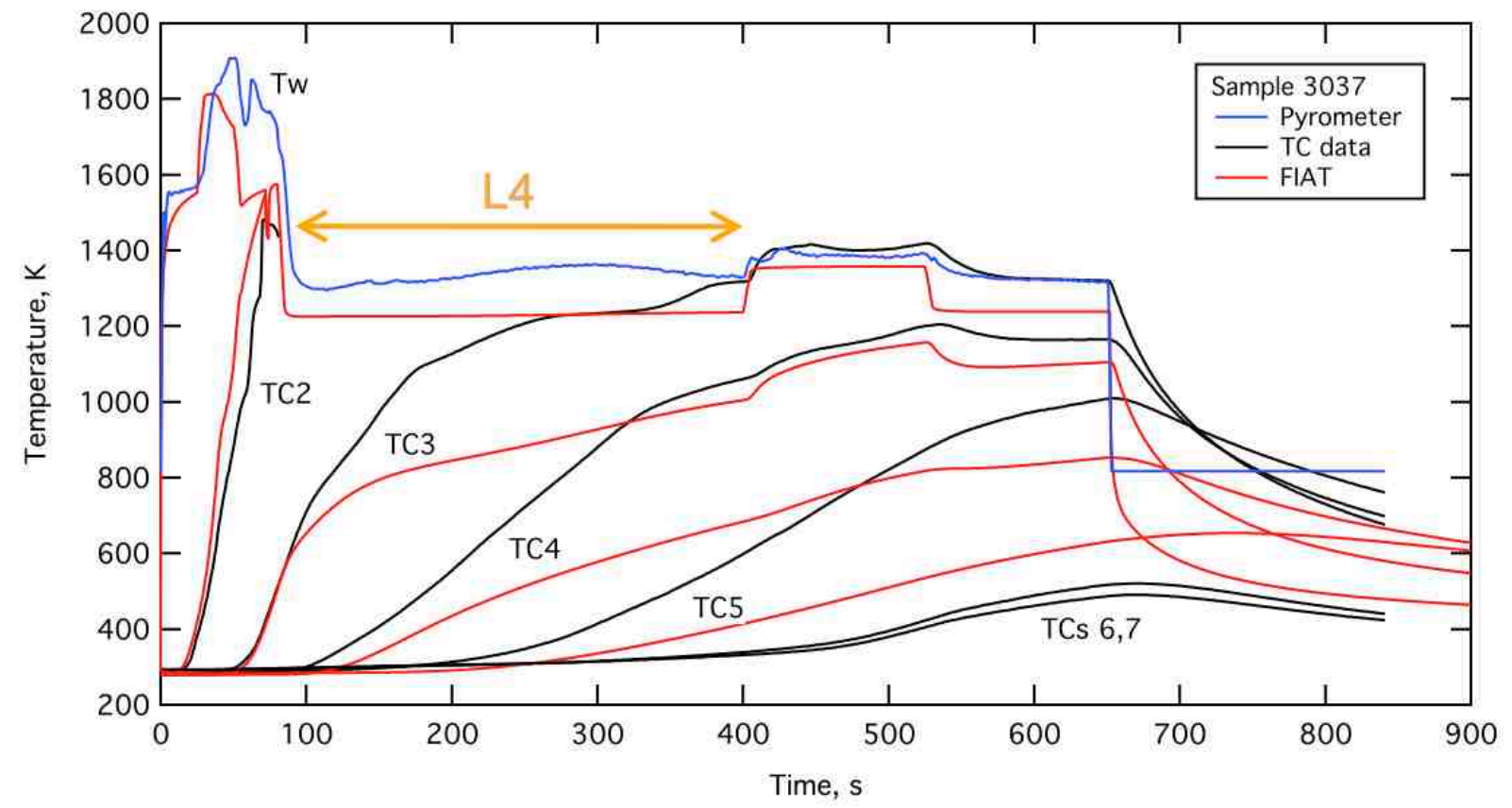

Figure 34. Data and predictions for surface and in-depth temperatures of sample 3037. 